\title{
Comparison of seasonal and intraseasonal variation of tropical climate in NCAR CCM2 GCM with two different cumulus schemes
}

\author{
K. Rajendran*, Ravi S. Nanjundiah, and J. Srinivasan
}

With 19 Figures

Received November 1, 2000

Revised June 20, 2001

\begin{abstract}
Summary
The seasonal and intraseasonal variation of tropical climate in National Center for Atmospheric Research (NCAR) Community Climate Model Version 2 (CCM2) General Circulation Model (GCM) has been examined using two different cumulus parameterization schemes, the moist convective adjustment scheme of Manabe et al. (1965) and the mass-flux scheme of Hack (1994). Ten-year simulations have been undertaken with each of these schemes with SST prescribed according to the monthly mean climatology. The seasonal mean rainfall in the tropics simulated by the moist convective adjustment scheme (MCA) scheme was found to be more realistic than the mass-flux (Hack) scheme. The more realistic simulation by the MCA scheme was found to be on account of the fact that the mean moist static energy of the lower troposphere in the MCA scheme was closer to the observations than in the Hack scheme. In both the schemes, the precipitation in the tropics increases montonically with precipitable water vapour when the precipitable water vapour is above $40 \mathrm{~mm}$. This is consistent with relationship between precipitation and precipitable water in the observations. The Hack scheme tends to simulate lower precipitation (for a given amount of precipitable water) when compared to observations.

The MCA scheme simulates the eastward migration of convective systems along the equator quite well, although the speed of propagation is somewhat low. The poleward migration of convective systems in the Indian region is more realistically simulated by the MCA scheme than the Hack scheme. This is because the latitudinal gradient of the mean moist static energy in the MCA scheme is more
\end{abstract}

\footnotetext{
* Present affiliation: Department of Meteorology, Florida State University, Tallahassee, Florida, 32306 USA.
}

realistic than in the Hack scheme. Over most of the tropics, simulation by the MCA scheme is more realistic on both seasonal and intraseasonal timescales.

\section{Introduction}

The sensitivity of the tropical climate to different types of convection parameterization have been studied by several investigators (e.g., Slingo et al., 1988; Sud et al., 1992; Zhang, 1994). Slingo et al. (1988) studied the sensitivity of the simulation of monsoon onset to cumulus parameterization using an operational European Centre Medium Range Weather Forecast (ECMWF) model with Kuo convection scheme (Kuo, 1974). The modification in the convection scheme was found to have significant impact on the simulation of the monsoon circulation and precipitation. Since the clouds interact strongly with radiation, the combination of changes in the radiation scheme and the convection scheme significantly improved the General Circulation Model (GCM) simulation. Sud et al. (1992) found that when the Arakawa and Schubert (1974) scheme is used in the Goddard Laboratory for Atmospheres (GLA) GCM, the simulation produces more active hydrological cycle over the monsoonal areas compared to the simulation without convection parameterization. Zhang (1994) compared a simulation with mass 
flux cumulus scheme to a simulation without any convection scheme in Canadian Climate Centre (CCC) model and found that convection had significant impact on the monsoon circulation and its associated precipitation.

Convection parameterization has also been found to have an impact effect on the simulation of the Madden Julian Oscillation (MJO) (Tokioka et al., 1988; Itoh, 1989; Park et al., 1990; Slingo et al., 1996; Wang and Schlesinger, 1999). Wang and Schlesinger (1999) have summarized all these studies and their study was based on perpetual March simulations of University of Illinois at Urbana-Champaign (UIUC) GCM with Arakawa Schubert scheme (Arakawa and Schubert, 1974), Kuo scheme (Kuo, 1974) and with moist convective scheme (Manabe et al., 1965). They suggested that the MJO simulation by the models is highly dependent on the relative humidity criterion used in these schemes. They also show the success of the National Center for Atmospheric Research (NCAR) Community Climate Model Version 2 (CCM2) in the Atmospheric Model Intercomparison Project (AMIP, which was forced with observed Sea Surface Temperatures for 1979-1988 period) in simulating MJO was related to the use of a three-layer mass flux scheme.

Most previous studies such as that by Slingo et al. (1996) have emphasized the interannual variations of the intraseasonal patterns. Wang and Schlesinger (1999) used perpetual simulations which also have limitations because the intraseasonal and seasonal patterns are strongly coupled. In this paper, we discuss the impact of convective parameterization on the simulation of tropical climate on seasonal and intraseasonal scales in the National Center for Atmospheric Research (NCAR) Community Climate Model Version 2 (CCM2) GCM with emphasis on the mechanisms governing the intraseasonal and seasonal patterns. To understand these interactions without the complexity introduced by interannual variations, we have conducted multi-year simulations with seasonally varying climatological Sea Surface Temperatures (SSTs).

The work of Gadgil and Sajani (1998), who analyzed tropical precipitation in AMIP simulation with particular emphasis on the simulation of the Indian summer monsoon on the seasonal scale, has shown that the Geophysical Fluid
Dynamics Laboratory (GFDL) model using the Moist Convective Adjustment (MCA) scheme of Manabe et al. (1965) was able to outperform most other models in the simulation of tropical precipitation even though these models used more sophisticated cumulus parameterization schemes. This clearly suggested that MCA scheme (which forces the atmospheric moisture and temperature profiles to the stable state) appears to have the capability to simulate the tropical rainfall more realistically. We also need to understand the behavior of these schemes not just in simulating the mean seasonal pattern but also their ability to simulate intraseasonal variations, i.e. whether they are able to simulate low-frequency (temporal) variations (30-90 day variations) at lower (spatial) wave numbers.

Results from the AMIP simulations do provide an insight into such behaviour, but since these models differ in just more than their cumulus parameterization schemes it will be useful to intercompare the results in a single model, by changing only the cumulus scheme between the MCA scheme and the more sophisticated fluxbased scheme of Hack (1994).

This paper is organized in the following way. Section 2 describes the model and the methodology, including the design of the experiments. Section 3 discusses the effect of convection parameterization on the simulation of seasonal mean precipitation and circulation over the tropics. The effect of change in the parameterization of convection on the seasonal cycle is presented in Sect. 4. Assessment of the simulations of major intraseasonal oscillations such as MJO and meridional propagations by the two versions of the model is given in Sects. 5 and 6. Section 7 summarizes the results.

\section{The model, data and methodology}

\subsection{The model}

A scalable parallel message-passing implementation of the National Centre for Atmospheric Research Community Climate Model, Version 2 (NCAR CCM2) developed by Argonne Oak Ridge National Laboratory (Drake et al., 1995) has been used in this study. This version of the model has been widely tested in the context of various climate studies (Hack et al., 1994; Kiehl 
et al., 1994; Lieberman et al., 1994; Zhang et al., 1994; Hahmann et al., 1995). The detailed documentation of the model can be found in Hack et al. (1993). We have compared the simulations with the Moist Convective Adjustment (MCA) scheme (Manabe et al., 1965) and with the plume-based Hack (1994) scheme (Hack) on seasonal and intraseasonal timescales.

In the MCA scheme, moist convective adjustment is employed to prevent the large-scale atmosphere from becoming statically unstable. At each time step, the atmospheric column is checked for moist instability layer by layer, starting from the lowest model layer. If the lapse rate between the two adjacent layers exceeds the moist adiabat, vertical mixing of heat and moisture is invoked and condensation is allowed during mixing. Any remaining supersaturation is then removed by large-scale condensation. As a result, the temperature and moisture profiles are adjusted towards moist adiabats. Thus, clearly the moist convective adjustment process is local in nature and the vertical transport of heat and moisture depends on the local instability of a layer.

With the Hack scheme it is assumed that clouds consist of successive plumes occupying three model layers in depth, with the first plume starting from the top of the boundary layer and the next one starting one layer above and so on. Each plume carries a certain amount of cloud mass from its base height and detrains a fraction in the model layer immediately above. The rest is detrained in the third layer from the plume base. The amount of the cloud base mass flux at each plume base is determined by the atmospheric instability. Also, there is a connection between the plumes starting at the lower levels and those starting at the upper level through the modification of the environmental air by the lower level plumes. Thus, in this scheme the adjustment is expressed explicitly in the mass flux form and is performed in three layers successively from bottom to top at each time step.

The MCA scheme has been in use in the GFDL GCM since 1965 and has been extensively used in climate simulations. Gadgil and Sajani (1998) have shown that the simulation of the mean seasonal precipitation in the tropics with the GFDL model (which uses that MCA scheme) is better than most other models. The Hack scheme was first used in the CCM2 and has also been included in later versions of the GCMs developed by NCAR. Kiehl et al. (1994) have shown that CCM2 model using the Hack scheme is successful in capturing major features of the large-scale circulation in the tropics.

\subsection{Data}

The SST and sea ice distributions were specified from climatological data and updated in the middle of each month. The SST data set used in the model is from Shea et al. (1990) and interpolated for each model time step between the mid-month values. Thus, the model is basically forced by the seasonal change of SST and the daily change of the solar declination angle with a fixed solar insolation of $1370 \mathrm{~W} / \mathrm{m}^{2}$ at the top of the model atmosphere. The model integration is started from the initial conditions corresponding to 1 September 1987 (an analysis data set provided by NCAR) and is integrated for 10 model years. The first 3 months of integrations was not considered for analysis, to remove the effect of model spin-up. Since the two sets of 10 year model integrations were performed with climatological SST each of the climate simulations can considered to be equivalent to a set of 10 ensembles of one year duration.

For comparison with model simulated precipitation, observed monthly precipitation data sets based on the merged analysis of precipitation (Xie and Arkin, 1997, henceforth referred to as "Xie-Arkin") were used. The interpolated NOAA (National Oceanographic and Atmospheric Administration) daily Outgoing Longwave Radiation (OLR) from 1979 to 1997 on a $2.5^{\circ}$ latitude-longitude grid has also been used (Liebmann and Smith, 1996). For validation of circulation fields and thermodynamic fields, reanalysis products (Kalnay et al., 1996) of National Centers for Environmental Prediction (NCEP)/ NCAR have been used.

For spectral analysis global datasets on daily scales for long periods (about 10 years) are required. But such datasets are not available for precipitation, hence we have used OLR as proxy for rainfall. For consistency we have compared model-generated OLR with observed OLR.

We have studied the capability of the model to simulate active-break cycles over the Monsoon 
zone by comparing the simulated precipitation with the daily rainfall dataset compiled by the India Meteorological Department (IMD) using 366 rainfall stations.

\subsection{Methodology}

Simulated seasonal and intraseasonal variation have been studied using harmonic analysis in both spatial and temporal dimensions. The ability of the model to simulate the intraseasonal variation has been examined by identifying dominant periodicities through power spectrum analysis. The simulation of the MJO propagation characteristics has been assessed using OLR and $200 \mathrm{hPa}$ circulation fields after applying 20-70 day Lanczos band-pass filter (Duchon, 1979) and their spectral characteristics using the space-time spectral technique (Hayashi, 1977, 1982).

\section{Seasonal mean simulation over the tropics}

The seasonal mean (10 year mean) precipitation with the Hack and MCA schemes for winter (DJF) and summer (JJA) seasons have been compared with the observed mean (1980-1995) precipitation in Figs. 1 and 2, respectively. The noticeable feature of the MCA simulation is the smaller precipitation over the major convective centers of the tropics such as South America, southern parts of Africa and Australian-Indonesian region during winter. This reduction in precipitation is also seen during the summer (Fig. 2d). Over the West Pacific and northern parts of South America, the precipitation with the MCA scheme is smaller and becomes comparable to the observed values in summer, whereas it underestimates the precipitation over northern parts of Africa. Over the Indian region, the precipitation has increased over the peninsular region and the precipitation is reasonable in most parts of the monsoon trough zone.

The increased skill in the simulation of seasonal mean precipitation by the MCA version can be seen from the difference in (Figs. 1d and 2d) the simulated precipitation (for winter and summer seasons) by the two models (MCA-Hack). In summer, precipitation is higher over the Indian region, East Pacific and over the Atlantic Inter Tropical Convergence Zone (ITCZ) region north of South America (which is almost absent in Hack) and lower over West Pacific and northern Parts of Africa and South America. Similarly, in winter the precipitation decreases over southern parts of Africa and South America and over the Indonesian-Australian region where the Hack scheme overestimates the precipitation. The precipitation increases over the equatorial Indian Ocean and over the South Pacific Convergence Zone (SPCZ) with the MCA scheme.

We have studied the ability of the models to simulate the mean seasonal precipitation using the Pattern Correlation Coefficient (PCC). This is a commonly used statistic for the quantification of pattern similarity (Sperber and Palmer, 1996; Taylor, 2001). The PCC between the two variables $F$ and $R$ is given by

$R=\frac{\frac{1}{N} \sum_{n=1}^{N}\left(F_{n}-\bar{F}\right)\left(R_{n}-\bar{R}\right)}{\sigma_{F} \sigma_{R}}$,

where $N$ is the total number of points in time and/ or space, $\bar{F}$ and $\bar{R}$ are the mean values and $\sigma_{F}$ and $\sigma_{R}$ are the standard deviation of $F$ and $R$, respectively. The correlation coefficient reaches a maximum value of 1 when for all $n,\left(F_{n}-\bar{F}\right)=$ $\alpha\left(R_{n}-\bar{R}\right)$, where $\alpha$ is a positive constant. When $\alpha=1$, the two fields are identical, otherwise they have same centered pattern of variation. It is to be noted that the correlation coefficient alone is not sufficient to determine whether the two patterns have the same amplitude of variation.

The impact of convection parameterization on the simulation of mean precipitation over different regions of the tropics is illustrated by comparing the pattern correlation coefficient (PCC) of the two simulations with respect to the observation. The regions have been selected based on the observed mean precipitation distribution during Northern Hemispheric summer and winter seasons. The summer (JJA) and winter (DJF) PCC from Hack and MCA simulations (calculated with respect to observed Xie-Arkin precipitation for the selected regions) have been shown in Fig. 3. The regions selected and their geographic locations are given in the caption of the figure.

In summer, the simulation by the MCA scheme is much better compared to that with the Hack scheme, globally and over most of the individual regions. 
December-February Mean Precipitation
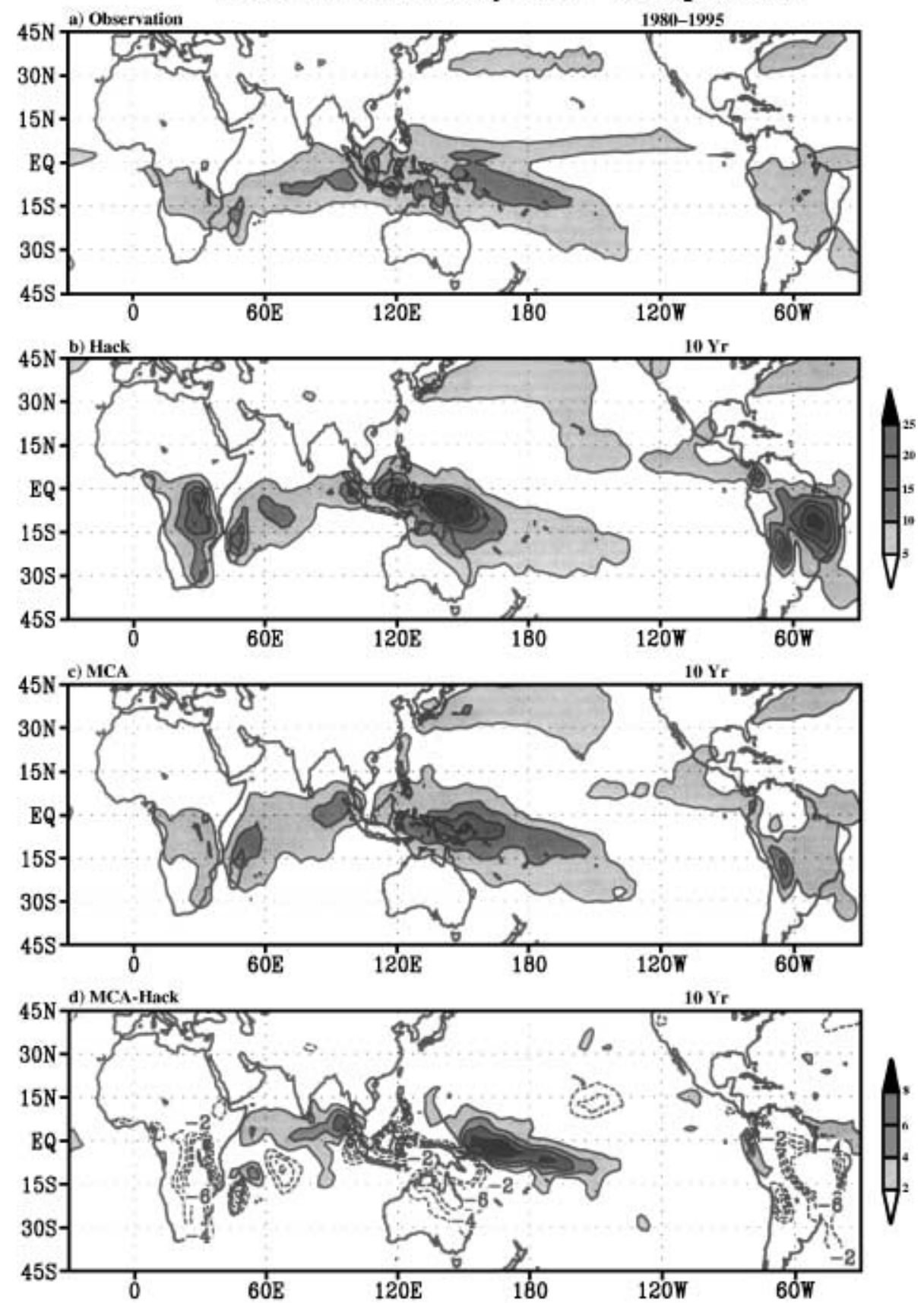

Fig. 1. Mean precipitation ( $\mathrm{mm}$ day $^{-1}$ ) for Northern Hemispheric winter (DJF) season for a observation (Xie-Arkin, 19801995), b Hack simulation (10 year), c MCA simulation (10 year), and $\mathbf{d}$ the 10 year mean difference between the winter mean Hack and MCA precipitation simulations (negative contours at $-2,-4,-6$, and -8 are shown dotted)
The PCC over the Indian region $\left(65^{\circ} \mathrm{E}-90^{\circ} \mathrm{E}\right.$; $10^{\circ} \mathrm{S}-30^{\circ} \mathrm{N}$, in Fig. 3) is higher in the MCA simulation (0.40) compared to the Hack simulation (0.24). Over the East Pacific, the maximum precipitation in the MCA scheme has shifted westwards and situated over the oceanic regions similar to the observation, but still weaker than the observation (west of $130^{\circ} \mathrm{W}$ ). The pattern correlation coefficient for this region $\left(130^{\circ} \mathrm{W}-\right.$ $\left.90^{\circ} \mathrm{W} ; 0-15^{\circ} \mathrm{N}\right)$, is much higher in the simula- tion with the MCA scheme (0.71) compared to that with the Hack scheme (0.47).

In winter, the MCA simulation is better correlated with observation over the global tropics and also regionally over Australia (AUS) and West Pacific (WPAC) which are the primary convective centres during the Northern Hemispheric winter season. The PCC is below 0.3 over SAFR and SAMR where the Hack scheme is better than the MCA scheme. There is 

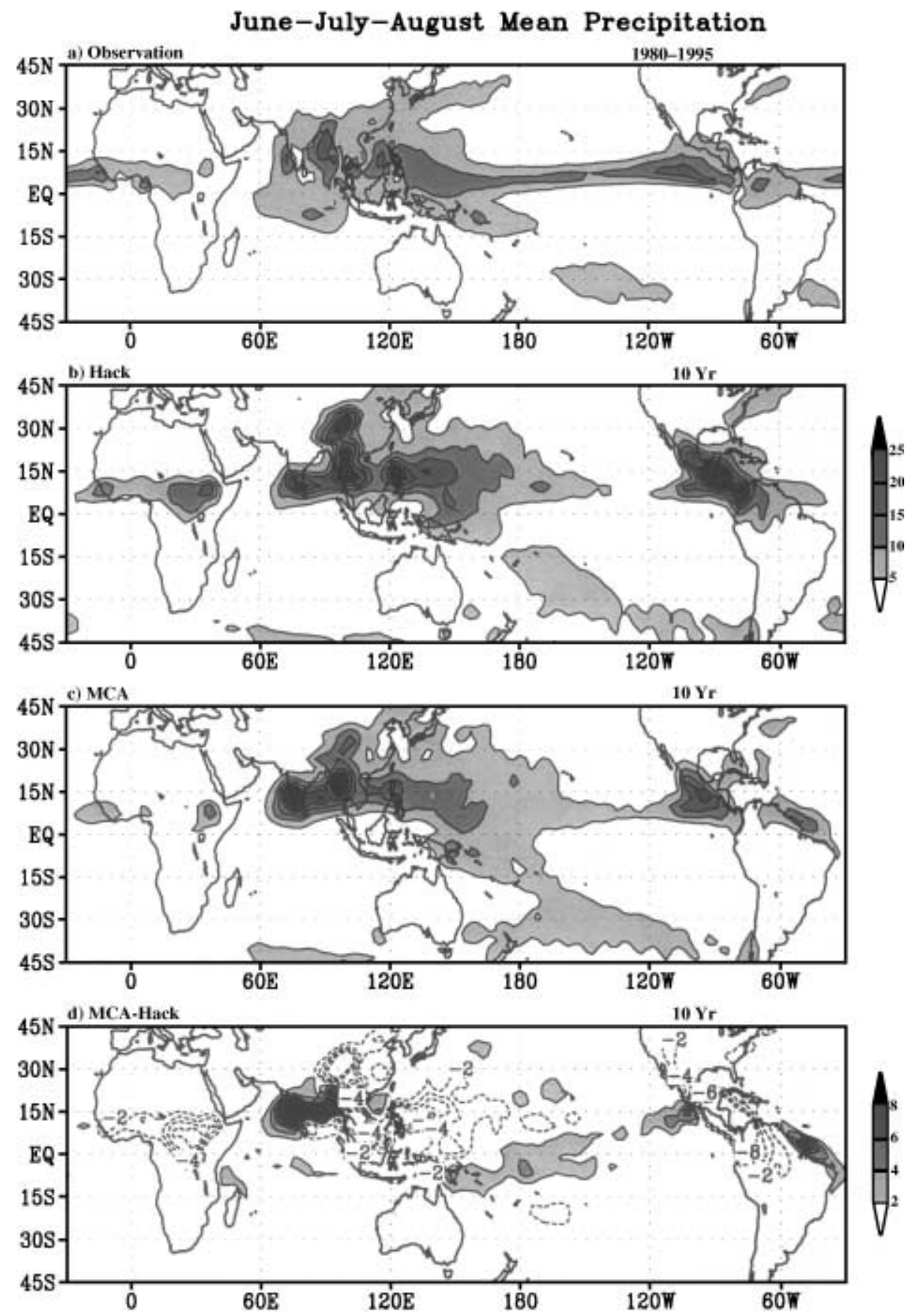

Fig. 2. Mean precipitation $(\mathrm{mm}$ day $^{-1}$ ) for Northern Hemispheric summer (JJA) season for a observation (Xie-Arkin, 19801995), b Hack simulation (10 year), c MCA simulation (10 year), and $\mathbf{d}$ the 10 year mean difference between the summer mean Hack and MCA precipitation simulations (negative contours at $-2,-4,-6$ and -8 are shown dotted)

a region of high rainfall over SAFR during DJF around $10^{\circ} \mathrm{S}$ and between $21^{\circ} \mathrm{E}-30^{\circ} \mathrm{E}$ in observations. Both MCA and Hack overestimate this rainfall. However, the Hack simulates a region of large rainfall around $10^{\circ}$ and $24^{\circ} \mathrm{E}-30^{\circ} \mathrm{E}$, while the region of high rainfall is displaced more northwards in the MCA simulation. This perhaps is the cause of the higher PCC over SAFR for the Hack simulation. Another noticeable feature is the lower PCC for MCA over the East Pacific where this scheme showed a marked improvement during summer.

\subsection{Relationship between precipitable water and rainfall}

Why is the simulation of monsoon precipitation by the MCA parameterization better than that of the Hack scheme in CCM2? Neelin and Held (1987), and Srinivasan and Smith (1996) have 


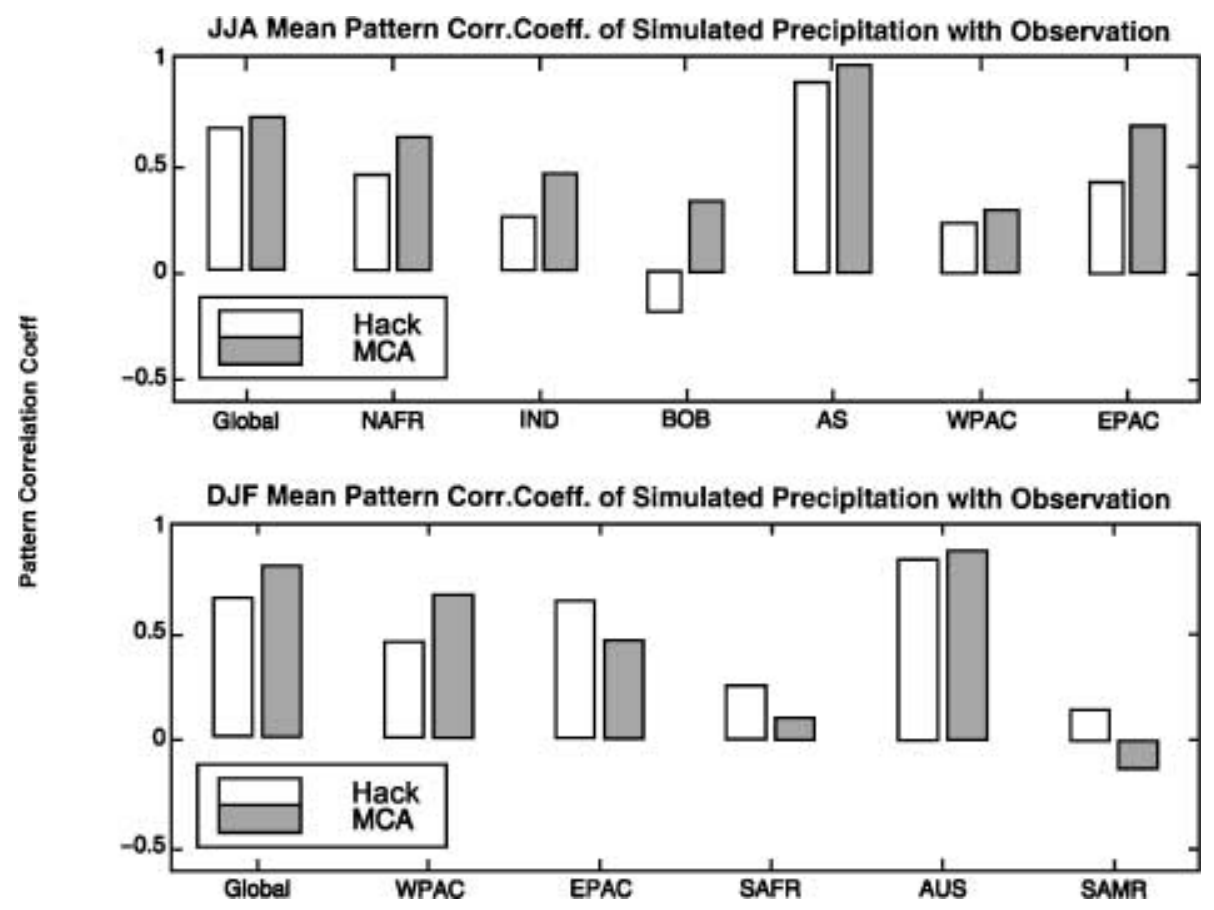

Fig. 3. Pattern correlation coefficient of June-July-August (top) and December-January-February (bottom) average precipitation with respect to observed Xie-Arkin precipitation for Hack and MCA simulations. The selected regions are: Global $\left(0-360^{\circ}, 30^{\circ} \mathrm{S}-30^{\circ} \mathrm{N}\right)$; North Africa, NAFR $\left(10^{\circ} \mathrm{E}-30^{\circ} \mathrm{E}, 0-12.5^{\circ} \mathrm{N}\right)$; Indian region $\left(65^{\circ} \mathrm{E}-90^{\circ} \mathrm{E}, 10^{\circ} \mathrm{S}-30^{\circ} \mathrm{N}\right)$; Bay of Bengal, BOB $\left(80^{\circ} \mathrm{E}-95^{\circ} \mathrm{E}, 7.5^{\circ} \mathrm{N}-17.5^{\circ} \mathrm{N}\right)$; Arabian Sea, AS $\left(55^{\circ} \mathrm{E}-70^{\circ} \mathrm{E}, 7.5^{\circ} \mathrm{N}-17.5^{\circ} \mathrm{N}\right)$; West Pacific, WPAC $\left(120^{\circ} \mathrm{E}-142.5^{\circ} \mathrm{E}, 5^{\circ} \mathrm{N}-17.5^{\circ} \mathrm{N}\right)$; East Pacific, EPAC $\left(90^{\circ} \mathrm{W}-130^{\circ} \mathrm{W}, 0-15^{\circ} \mathrm{N}\right)$; South Africa, SAFR $\left(15^{\circ} \mathrm{E}-35^{\circ} \mathrm{E}\right.$, $\left.15^{\circ} \mathrm{S}-2.5^{\circ} \mathrm{S}\right)$; Australia, AUS $\left(122.5^{\circ} \mathrm{E}-142.5^{\circ} \mathrm{E}, 25^{\circ} \mathrm{S}-15^{\circ} \mathrm{S}\right)$; South America, SAMR $\left(45^{\circ} \mathrm{W}-67.5^{\circ} \mathrm{W}, 15^{\circ} \mathrm{S}-2.5^{\circ} \mathrm{S}\right)$

shown that the precipitation in the tropics depends upon the mean moist static energy of the lower troposphere. The mean moist static energy of the lower troposphere is defined as the sum of sensible heat, potential energy and latent heat, i.e.

$m_{l}=\int_{400}^{1000}\left(C_{p} T+g z+L q\right) d p$,

where $m_{l}$ is the mean moist static energy of the lower troposphere, $T$, the temperature, $z$ the height, $q$ the specific humidity and $L$ the latent heat of evaporation.

Srinivasan and Smith (1996) have shown that the mean moist static energy threshold for deep convection is around $335 \mathrm{~kJ} / \mathrm{kg}$ for both continents and oceans. The mean moist static energy is a crucial factor in determining the nature of tropical convection and precipitation processes (e.g., Zhang 1994; Nanjundiah, 2000; Nanjundiah and Srinivasan, 1999).

The precipitable water from NCEP/NCAR reanalysis and the two model simulations are shown for DJF (Fig. 4a) and JJA (Fig. 4b). The MCA simulation tends to simulate lower precipitable water (pwat) vis-a-vis the Hack scheme over Western Pacific during both DJF and JJA seasons. Both appear to over-estimate precipitable water vis-a-vis reanalysis.

The differences between observed (based on NCEP/NCAR reanalysis) and simulated moist static energy of the lower troposphere $\left(m_{l}\right)$ during the boreal summer (JJA) season for the two versions of the model (shown in Fig. 4c) suggest that the error in the $m_{l}$ over the seasonal convective centres of the tropics is small for the MCA scheme. The improvement in the simulation with MCA scheme is more pronounced over North Africa (NAFR), eastern Asia-West Pacific region and East Pacific (EPAC). With the Hack scheme, the errors in $m_{l}$ is larger compared to the those with the MCA scheme over all these regions where the precipitation simulated by the MCA scheme was also found to be better correlated with observation (higher PCC for MCA in Fig. 3). 

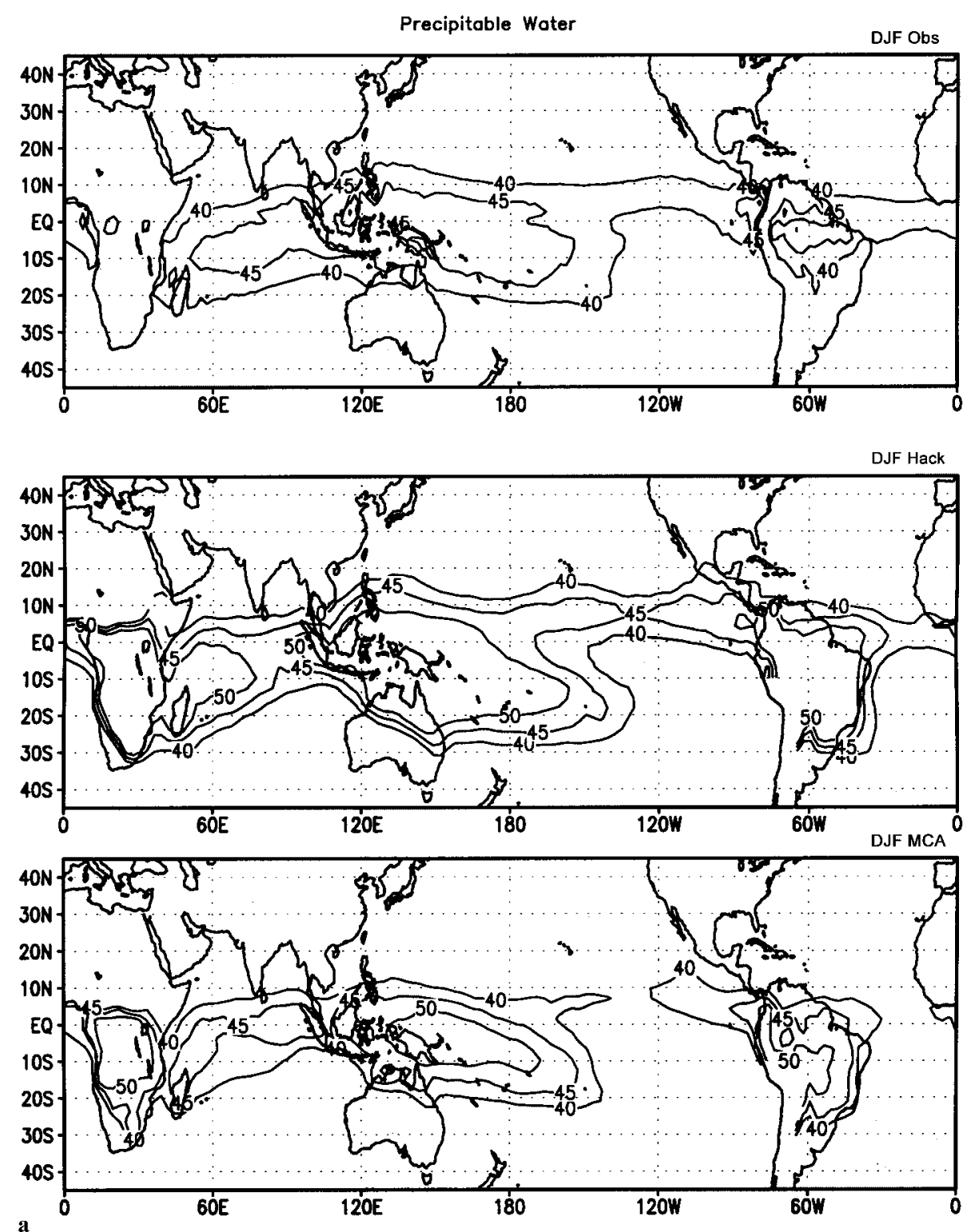

Fig. 4a. Precipitable water (mm) during DJF from (i) NCEP/ NCAR Reanalysis, (ii) Hack, and (iii) MCA

Equation 2 indicates that variations of $m_{l}$ are directly related to the variations of the specific humidity integrated over the lower troposphere, i.e. precipitable water (as most of the water vapour occurs in the lower troposphere). The difference patterns of precipitation, $m_{l}$ and precipitable water (pwat) between the MCA and Hack schemes for July of the third year of integration are shown in Fig. 5. We find that the differences in precipitation are associated with differences in $m_{l}$ which in turn is associated with the differences in precipitable water. Regions with higher pwat and $m_{l}$ in the MCA scheme agree well with regions of higher precipitation in this scheme and vice-versa.
To further understand the differences between the two simulations and also with observations we examine the relationship between precipitable water and precipitation (Fig. 6) for the entire tropical regions $\left(0-360,25^{\circ} \mathrm{N}-25^{\circ} \mathrm{S}\right)$ and the 10 years of simulation. For observations we use NCEP/NCAR Re-analysis (Kalnay et al., 1996) precipitable water and Xie and Arkin (1997) rainfall for the period 1982-1994.

Note that rainfall increases monotonically with precipitable water when its is above $40 \mathrm{~mm}$. This is the threshold value of precipitable water below which precipitation remains low. Beyond this value there is a rapid increase in precipitation. 

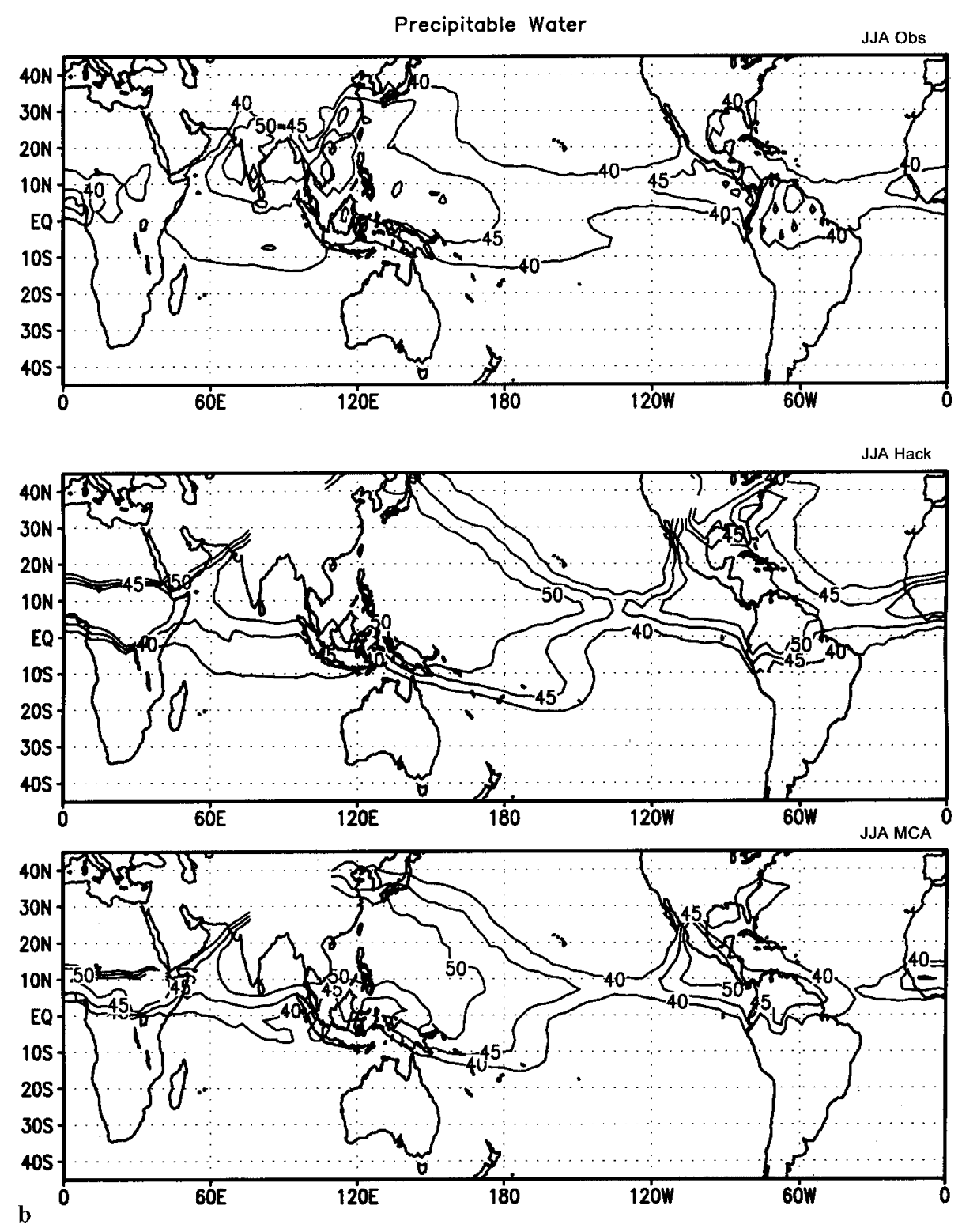

Fig. 4b. Same as Fig. 4a, but for JJA

We also notice that the response of MCA vis-avis observations is different over oceanic and continental regions. Over oceanic regions, for the same value of precipitable water, MCA values are in good agreement with observations. The same scheme underestimates however, the precipitation over continental regions. The Hack scheme in contrast consistently underestimates the precipitation over both continental and oceanic regions. It is also interesting to note that the Hack scheme appears to simulate unrealistically high values of precipitation and precipitable water, occur primarily over the East-Asia and West Pacific region. Comparing the vertical profiles of specific humidity, we notice that the Hack scheme has unrealistically higher specific humidity over this region (Fig. 7, during July of Year 3).

\subsection{Circulation pattern}

The models simulate the circulation fields over the tropics reasonably well. Prominent features during JJA at $850 \mathrm{hPa}$ such as the centres of lowlevel divergence associated with the subtropical high pressure belt and a well-developed Asian summer monsoon system with strong crossequatorial flow from the Southern Hemisphere 

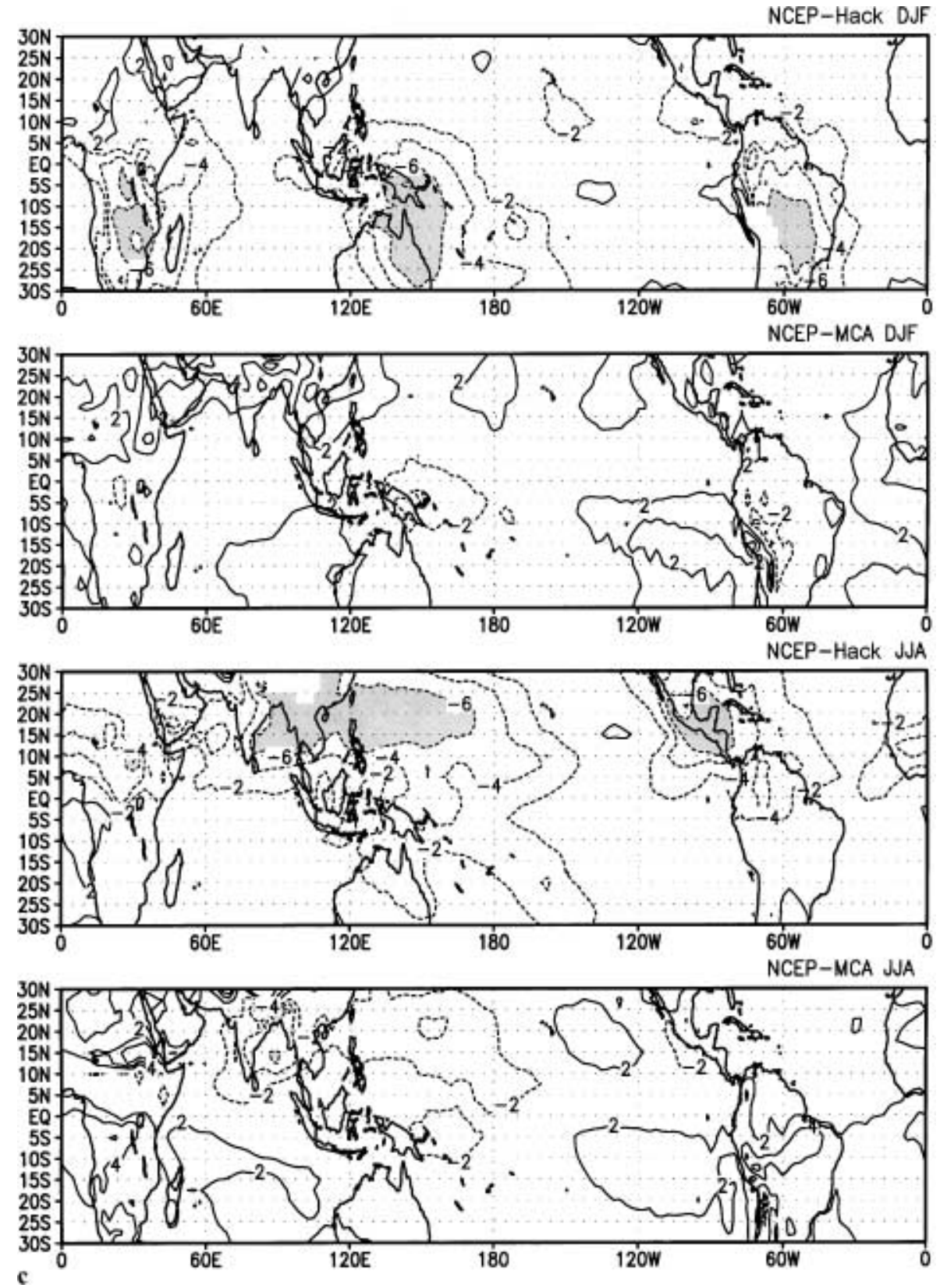

Fig. 4c. The difference patterns of vertically integrated moist static energy in the layer 1000$400 \mathrm{hPa}\left(m_{l}\right)$ for (i) Hack simulation, and (ii) MCA simulation with respect to $m_{l}$ based on NCEP/NCAR reanalysis (in $\mathrm{kJ}$ $\mathrm{kg}^{-1}$ ) for DJF (top) and JJA (bottom) seasons across the east African coast are realistically captured by the models. The magnitudes of lowlevel winds (indicated by the shadings in the Fig. 8) are however much higher in the simulations. The major difference between the two simulations occurs over the southeast Asian region where the simulated trough coinciding with the centre of westerly confluence is located slightly northwards in the MCA simulation, similar to that in the NCEP/NCAR reanalysis. Both versions of the model simulate the major features such as the upper level subtropical westerly jets (with centres slightly shifted poleward of the observed position), low-level westerly jet over the Indian region with observed maximum at $850 \mathrm{hPa}$ and the strong easterly jet at the upper troposphere between $0-20^{\circ} \mathrm{N}$. The magnitudes of simulated winds are markedly higher compared to the observation. Over the Indian landmass (between $10^{\circ} \mathrm{N}-20^{\circ} \mathrm{N}$ ), the westerlies are stronger in the MCA simulation (compared to the Hack simulation) in the layer stretching from 1000-600 $\mathrm{hPa}$. Additionally, the position of Tropical Easterly Jet (TEJ) is shifted 

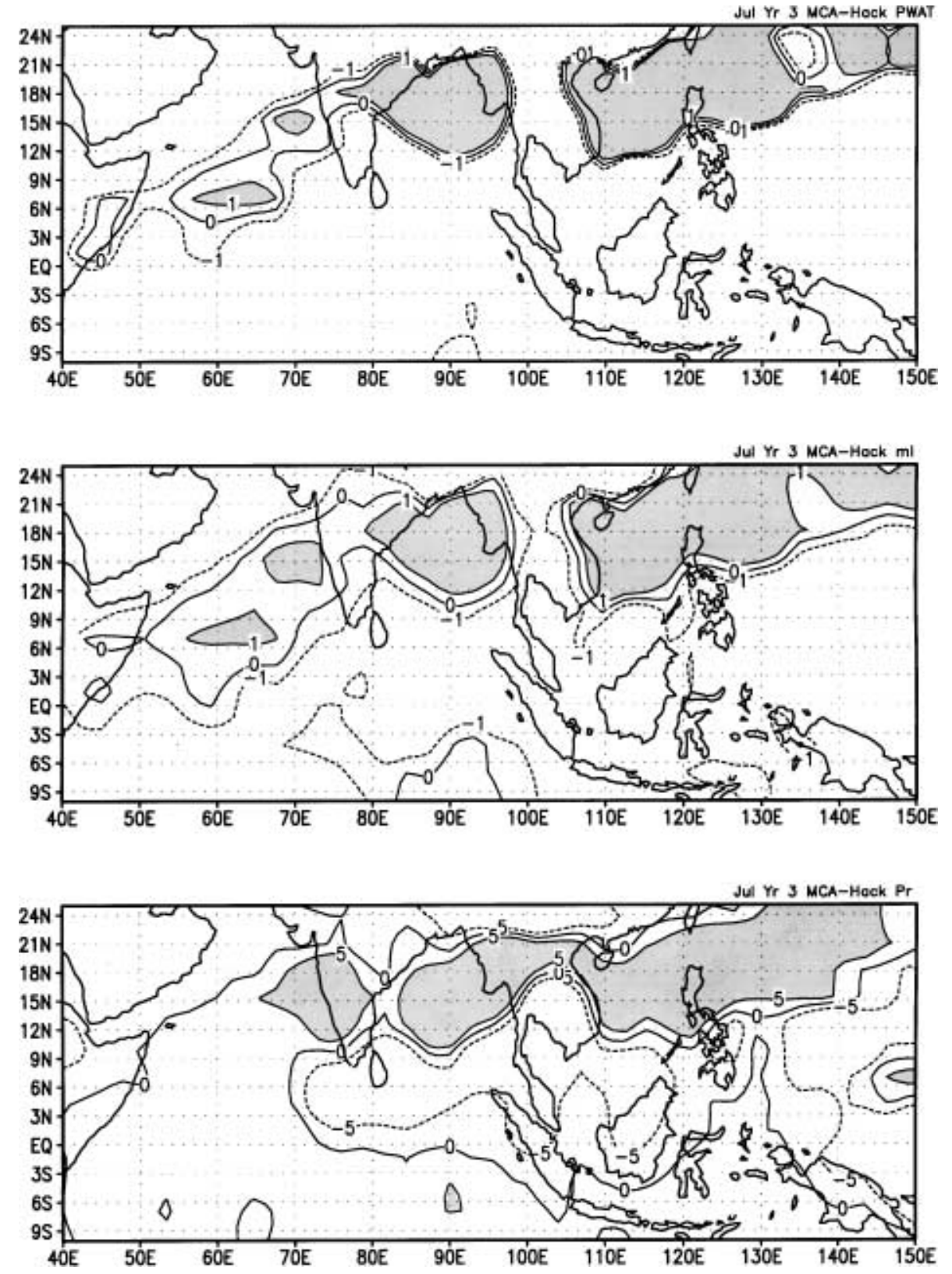

Fig. 5. Differences in precipitable water (mm, Pwat), vertically integrated moist static energy $(\mathrm{kJ}$ $\left.\mathrm{kg}^{-1}, m_{l}\right)$ and precipitation $(\mathrm{mm}$ day $^{-1}$, Pr) between the MCA and the Hack simulations for the July of year 3

northwards of the observed position in the Hack simulation whereas in MCA simulation, the TEJ location is more realistic compared to observation. The structure of westerly maximum in the lower troposphere over the oceanic region between equator to $10^{\circ} \mathrm{N}$ (where both versions of the model fail to simulate realistic precipitation) is very different from the observation for both the models.

The over-estimation of wind in the models is on account of the response of the tropical atmosphere to the higher precipitation rates (and hence higher heating rates) in the model. The more intense precipitation and associated latent heating (in the MCA simulation) produces stronger convergence and stronger winds in the models. The maximum westerly wind in the layer extending from $1000 \mathrm{hPa}$ to $850 \mathrm{hPa}$ during the summer (JJA) season over the Asian monsoon region $\left(60^{\circ} \mathrm{E}-\right.$ $\left.110^{\circ} \mathrm{E} ; 0^{\circ}-25^{\circ} \mathrm{N}\right)$ plotted against the corresponding area average summer (JJA) mean precipitation for each year shows the association between the strength of the low level westerly wind and precipitation (Fig. 9). In models, the simulated 


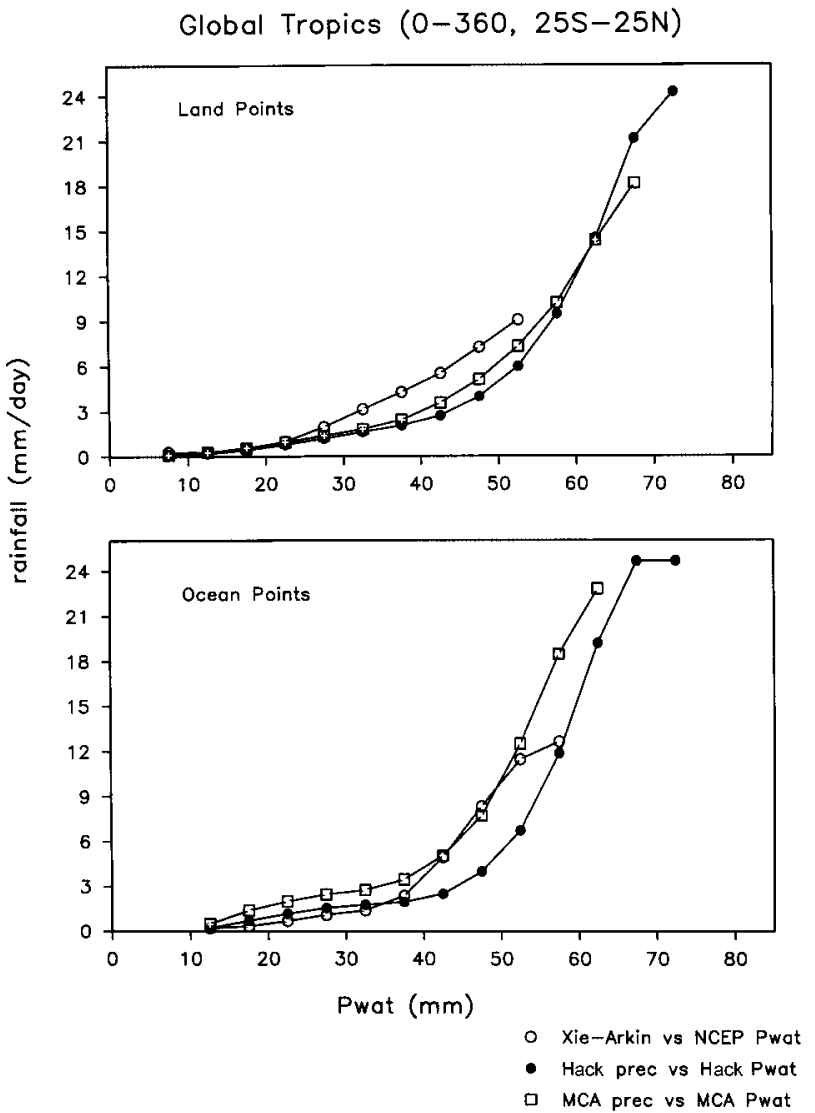

Fig. 6. Relationship between precipitation $\left(\mathrm{mm} \mathrm{day}^{-1}\right)$ and precipitable water $(\mathrm{mm})$ in the tropics over a continental regions, and $\mathbf{b}$ over oceanic regions, for observations, MCA and Hack simulations

precipitation and winds are stronger than the observation and the magnitude of wind linearly increases with the corresponding precipitation rate. This is consistent with the simple model for tropical circulation proposed by Gill (1980). Hurrel (1995) has also noted that winds are overestimated by this model.

\section{Simulation of seasonal cycle over the tropics}

Simulations of seasonal and intraseasonal variations have been studied by applying harmonic analysis to the observed and simulated daily OLR datasets. The observed and simulated OLR datasets for each year have been separated into three different classes based on the frequency bands by applying harmonic analysis. The sum of the first four harmonics represents the "seasonal cycle" (corresponding to time periods

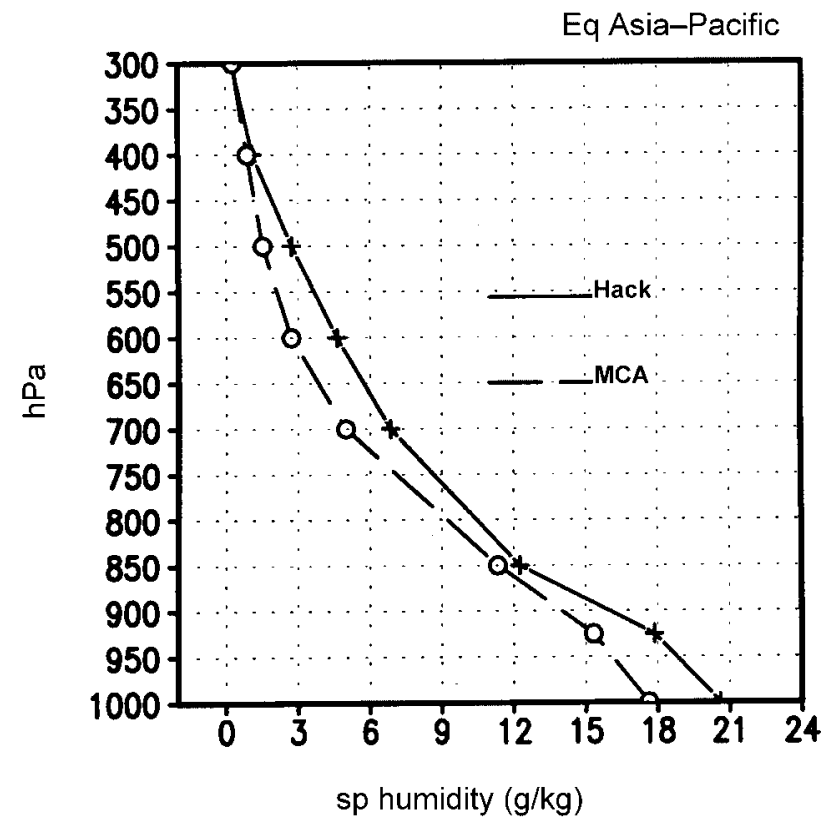

Fig. 7. Vertical profile of specific humidity $\left(\mathrm{g} \mathrm{kg}^{-1}\right)$ over the equatorial Asia-Pacific region $\left(100^{\circ}-120^{\circ}, 0^{\circ}-10^{\circ}\right)$ during July of year 3 " + " indicates the Hack scheme, open circles are for the MCA scheme

up to 90 days) and the sum of 5 to 12 harmonics constitutes the "intraseasonal cycle" (comprising periods 30 to 70 days) and the residual represents the transient eddies in the harmonic analysis, i.e. for any variable, $V$,

$V(t)=\bar{V}+S(t)+I S(t)+H F(t)+$ Residual

where,

$$
\begin{aligned}
S(t) & =\sum_{m=1}^{4} V_{m} \exp \left(i \frac{2 \pi m}{T} t\right), \\
I S(t) & =\sum_{m=5}^{12} V_{m} \exp \left(i \frac{2 \pi m}{T} t\right), \\
H F(t) & =\sum_{m=13}^{72} V_{m} \exp \left(i \frac{2 \pi m}{T} t\right) .
\end{aligned}
$$

Here, $\bar{V}$, represents the annual mean for a particular year, $V_{m}$ denotes the amplitude of $m^{\text {th }}$ harmonic, $t$ is time in days and $T$ is 365 days. $S(t)$ represents the seasonal cycle, $I S(t)$ represents the intraseasonal cycle and $H F(t)$ represents the higher frequency components (5-30 days) while "Residual" represents harmonics with timeperiods less than 5 days. Our analysis closely follows that of Murakami et al. (1986). While 

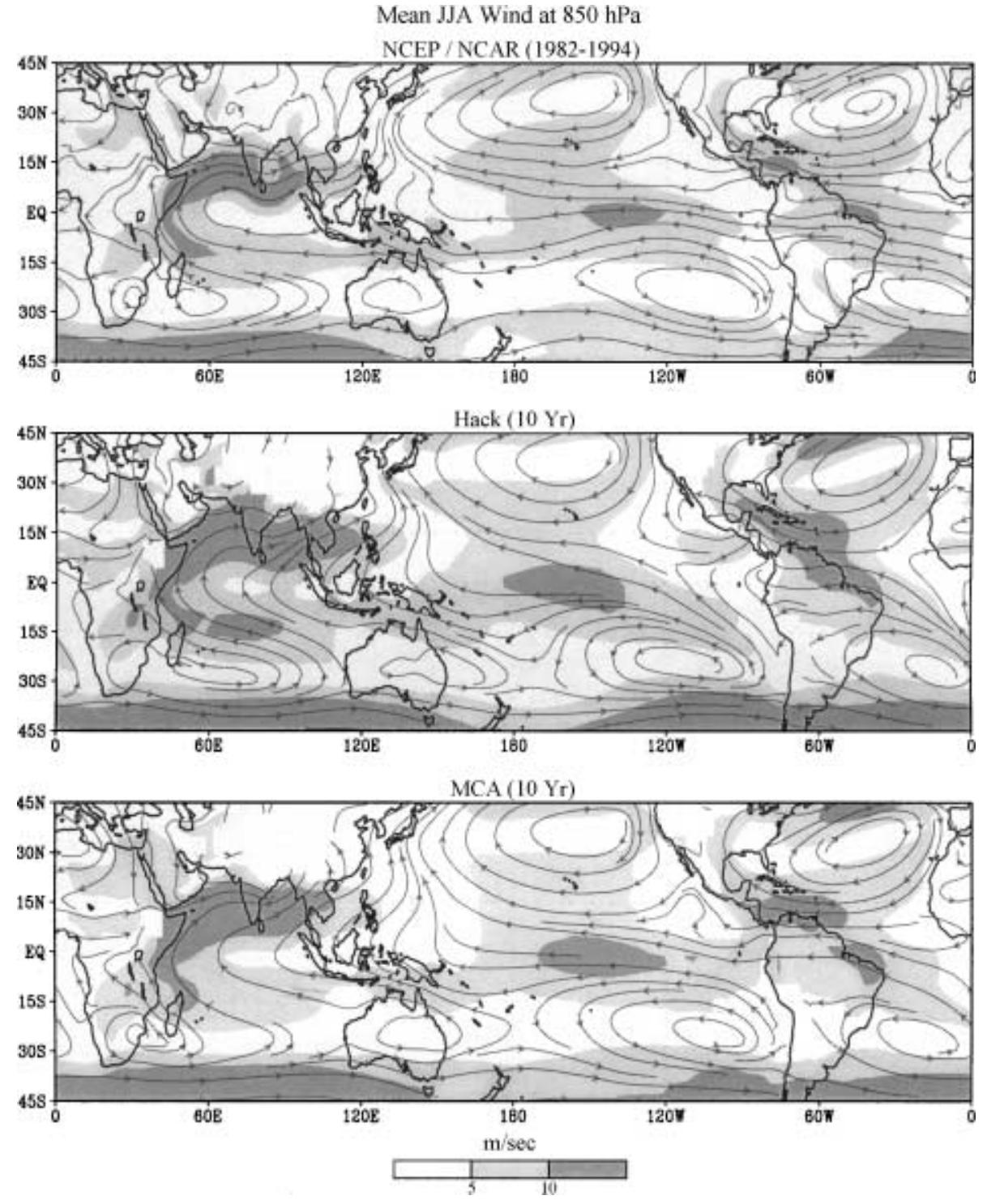

Fig. 8. Streamlines for Northern Hemispheric summer (JJA) mean winds $\left(\mathrm{m} \mathrm{sec}^{-1}\right)$ at $850 \mathrm{hPa}$ from (i) NCEP/NCAR reanalysis (top), and (ii) Hack (middle), and (iii) MCA simulations. The shaded contours indicate wind magnitudes they used harmonic analysis only for observational data, we have used this for studying simulated OLR also.

Harmonic analysis was applied to each year separately for observed OLR data from 1980 to 1989 and 10 year simulations of two versions of the model. For assessing the performance of the two schemes in simulating the mean climate over the tropics, we had used observed OLR data for the period 1980-1995. But, it was found that the structure of the harmonics (i.e., the mean of the individual harmonic over the period) were largely insensitive to period of the OLR data, e.g. the structure was largely similar for the OLR datasets of 1980-1989 and 1980-1995.

\subsection{Harmonic analysis}

The simulation of seasonal cycle over selected regions of the tropics (shown in Fig. 10) have been studied using harmonic analysis. These regions have been selected to represent major centres of convection in the tropics. The seasonal cycle was constructed as the sum of first four harmonics of OLR averaged over these regions (denoted as $\mathrm{S}(\mathrm{t})$ hereafter). Figure 11 shows the 10 year mean seasonal cycle (i.e. the harmonics are calculated separately for each year and the mean of the ten years' first four harmonics are shown) for these regions from observation and from the simulations by Hack and MCA versions. 


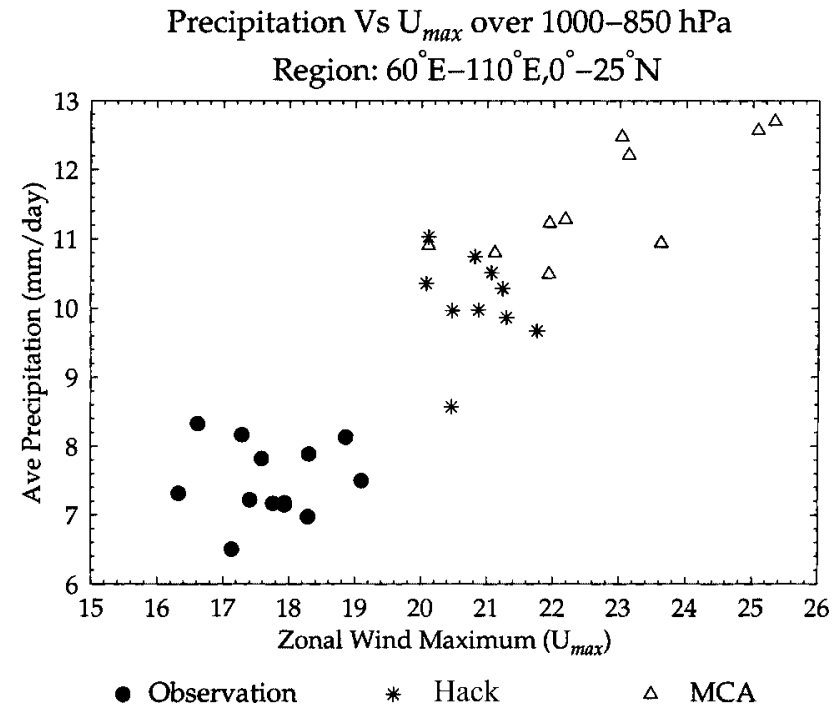

Fig. 9. The observed (Xie-Arkin) and simulated (Hack and MCA) area averaged June-July-August mean precipitation over $60^{\circ} \mathrm{E}-110^{\circ} \mathrm{E} ; \quad 0^{\circ}-25^{\circ} \mathrm{N}\left(\mathrm{mm} \mathrm{day}{ }^{-1}\right)$ plotted as function of respective westerly wind maxima $\left(\mathrm{m} \mathrm{sec}^{-1}\right)$ out of the three lower layers $(1000,925,850 \mathrm{hPa})$ over the same region. The observed westerly wind maximum is computed from the NCEP/NCAR reanalysis for the period 1982-1994
Over the Asian monsoon region, monsoon onset generally occurs with the phase change of $S(t)$ from dry winter phase (positive) to wet summer phase (negative). On the other hand, the withdrawal takes place with the phase transition from negative to positive. Over the Monsoon zone (MZ) and the Bay of Bengal (BOB), Hack shows a slightly late onset compared to MCA. Over Monsoon zone, the phase and amplitude of the seasonal cycle during monsoon and pre-monsoon seasons are closer to the observation for MCA. Over Bay of Bengal, the duration of monsoon season is clearly longer for the MCA simulation. However, the withdrawal is faster in the MCA simulation. During monsoon season, the amplitude of seasonal cycle is less for MCA compared to Hack but higher than observed.

Over the oceanic regions of Arabian Sea (AS), West Pacific (WPAC) and East Pacific (EPAC) the simulation of onset is closer to the observation in the MCA simulation. One noticeable feature is the improvement in the simulation of the phase changes in the seasonal cycle over the

\section{Regions Considered for Analysis}

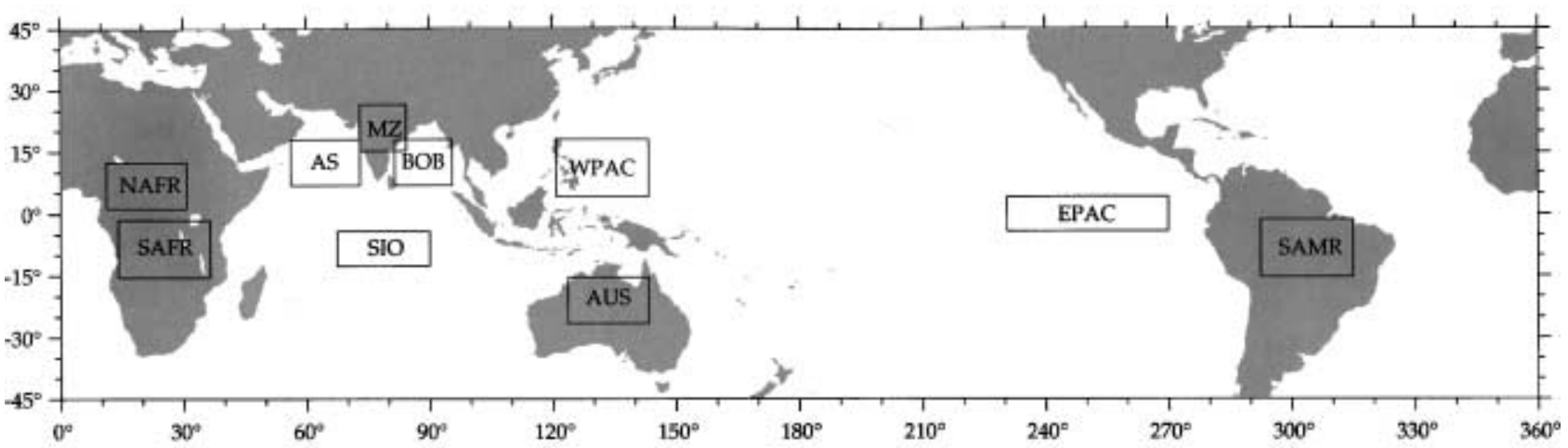

OBSERVATION

$$
\begin{aligned}
& \mathrm{MZ} \Rightarrow 72.5^{\circ} \mathrm{E}-85.0^{\circ} \mathrm{E} ; 15.0^{\circ} \mathrm{N}-25.0^{\circ} \mathrm{N} \\
& \text { BOB } \Rightarrow 80.0^{\circ} \mathrm{E}-95.0^{\circ} \mathrm{E} ; 7.5^{\circ} \mathrm{N}-17.5^{\circ} \mathrm{N} \\
& \mathrm{AS} \Rightarrow 55.0^{\circ} \mathrm{E}-72.5^{\circ} \mathrm{E} ; 7.5^{\circ} \mathrm{N}-17.5^{\circ} \mathrm{N} \\
& \text { SIO } \Rightarrow 67.5^{\circ} \mathrm{E}-90.0^{\circ} \mathrm{E} ; 12.5^{\circ} \mathrm{N}-5.0^{\circ} \mathrm{S} \\
& \text { AUS } \Rightarrow 122.5^{\circ} \mathrm{E}-142.5^{\circ} \mathrm{E} ; 25.0^{\circ} \mathrm{S}-15.0^{\circ} \mathrm{S} \\
& \text { WPAC } \Rightarrow 120.0^{\circ} \mathrm{E}-142.5^{\circ} \mathrm{E} ; 5.0^{\circ} \mathrm{N}-17.5^{\circ} \mathrm{N} \\
& \text { EPAC } \Rightarrow 130.0^{\circ} \mathrm{W}-90.0^{\circ} \mathrm{W} ; 5.0^{\circ} \mathrm{S}-5.0^{\circ} \mathrm{N} \\
& \text { NAFR } \Rightarrow 10.0^{\circ} \mathrm{E}-30.0^{\circ} \mathrm{E} ; 0.0^{\circ}-12.5^{\circ} \mathrm{N} \\
& \text { SAFR } \Rightarrow 15.0^{\circ} \mathrm{E}-35.0^{\circ} \mathrm{E} ; 15.0^{\circ} \mathrm{S}-2.5^{\circ} \mathrm{S} \\
& \text { SAMR } \Rightarrow 67.5^{\circ} \mathrm{W}-45.0^{\circ} \mathrm{W} ; 15.0^{\circ} \mathrm{S}-2.5^{\circ} \mathrm{S}
\end{aligned}
$$

MODEL

$$
\begin{aligned}
& \mathrm{MZ} \Rightarrow 73.1^{\circ} \mathrm{E}-84.4^{\circ} \mathrm{E} ; 15.3^{\circ} \mathrm{N}-26.5^{\circ} \mathrm{N} \\
& \mathrm{BOB} \Rightarrow 81.6^{\circ} \mathrm{E}-95.6^{\circ} \mathrm{E} ; 7.0^{\circ} \mathrm{N}-18.1^{\circ} \mathrm{N} \\
& \mathrm{AS} \Rightarrow 56.3^{\circ} \mathrm{E}-73.1^{\circ} \mathrm{E} ; 7.0^{\circ} \mathrm{N}-18.1^{\circ} \mathrm{N} \\
& \text { SIO } \Rightarrow 67.5^{\circ} \mathrm{E}-90.0^{\circ} \mathrm{E} ; 12.3^{\circ} \mathrm{N}-4.2^{\circ} \mathrm{S} \\
& \text { AUS } \Rightarrow 123.8^{\circ} \mathrm{E}-143.4^{\circ} \mathrm{E} ; 26.5^{\circ} \mathrm{S}-15.3^{\circ} \mathrm{S} \\
& \text { WPAC } \Rightarrow 120.9^{\circ} \mathrm{E}-143.4^{\circ} \mathrm{E} ; 4.2^{\circ} \mathrm{N}-18.1^{\circ} \mathrm{N} \\
& \text { EPAC } \Rightarrow 130.6^{\circ} \mathrm{W}-90.0^{\circ} \mathrm{W} ; 4.2^{\circ} \mathrm{S}-4.2^{\circ} \mathrm{N} \\
& \text { NAFR } \Rightarrow 11.3^{\circ} \mathrm{E}-30.9^{\circ} \mathrm{E} ; 1.4^{\circ} \mathrm{N}-12.6^{\circ} \mathrm{N} \\
& \text { SAFR } \Rightarrow 14.1^{\circ} \mathrm{E}-36.6^{\circ} \mathrm{E} ; 15.3^{\circ} \mathrm{S}-1.4^{\circ} \mathrm{S} \\
& \text { SAMR } \Rightarrow 67.5^{\circ} \mathrm{W}-45.0^{\circ} \mathrm{W} ; 15.3^{\circ} \mathrm{S}-1.4^{\circ} \mathrm{S}
\end{aligned}
$$

Fig. 10. The regions selected for power spectrum analysis. The domain for each region (denoted by respective abbreviation) is given for observation and model 
Mean OLR Anomaly Based on First 4 Harmonics

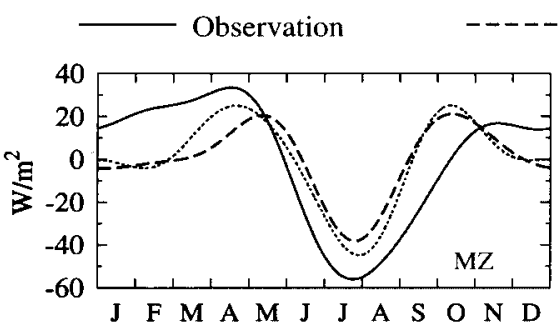

CCM2 Hack

$\mathrm{CCM} 2 \mathrm{MCA}$
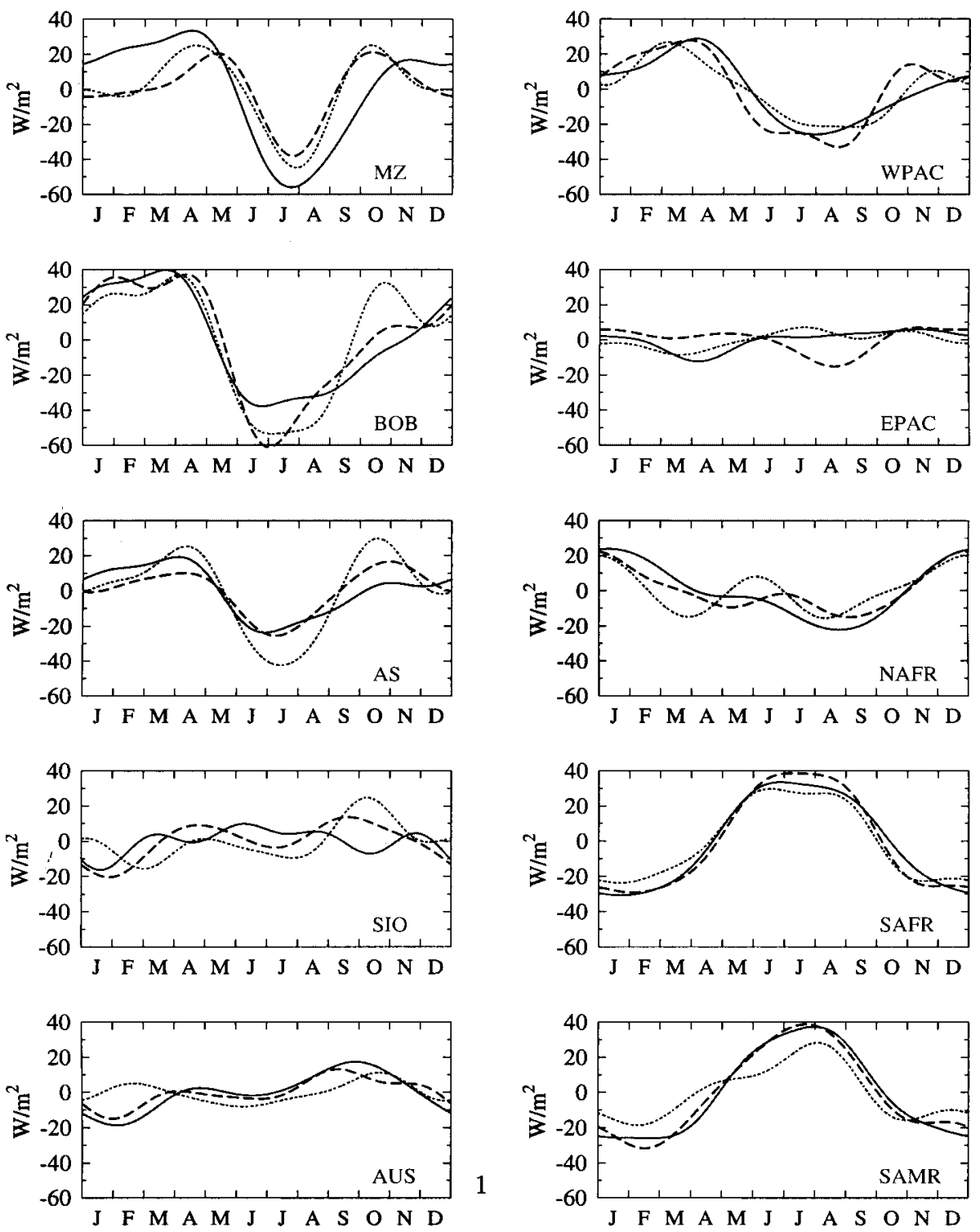
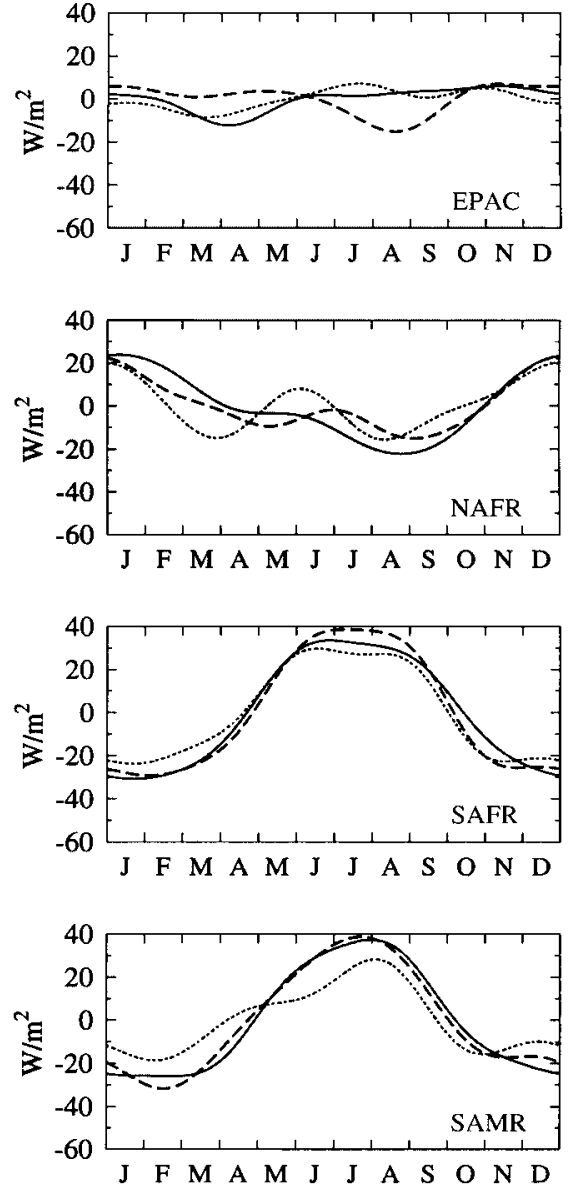

Fig. 11. The amplitude of the observed and simulated seasonal cycle (sum of first 4 harmonics, $\mathrm{S}(\mathrm{t}))$ of OLR for the 10 regions analyzed
East Pacific by the MCA version. But over the Southern Hemispheric monsoonal regions of Australia (AUS) and South America (SAMR) the Hack simulation is in better agreement with the observation. Over the southern Africa (SAFR), both versions of the model simulate the observed seasonal cycle. Whereas, over southern Indian Ocean (SIO $67.5^{\circ} \mathrm{E}-92.5^{\circ} \mathrm{E}$, $12.5^{\circ} \mathrm{S}-0$ ) and NAFR where the seasonality of mean convection is observed to be small, the simulations do not agree with observations. Over South Indian Ocean (SIO) in particular, the simulations are out of phase and differ in magnitude compared to the observation. Thus, although the spatial distribution and the phase and amplitude of seasonal cycle over the Asian monsoon region are simulated well by the MCA version of the model, over some parts of the tropics such as Australia and South America, the seasonal cycle simulation is better in the Hack version of the model.

\section{Simulation of intraseasonal variability over the tropics}

The simulation of intraseasonal variation has been studied by using power spectrum analysis of the simulated daily OLR averaged over 10 
Table 1. Number of years in which significant spectral peak occurs in observed and simulated OLR (after removing the first three harmonics) on intraseasonal time scale (20-70 days)

\begin{tabular}{lcll}
\hline Regions & $\begin{array}{l}\text { Observation } \\
\text { (out of 10) }\end{array}$ & $\begin{array}{l}\text { Hack } \\
\text { (out of 10) }\end{array}$ & $\begin{array}{l}\text { MCA } \\
\text { (out of 10) }\end{array}$ \\
\hline $\begin{array}{l}\text { Monsoon Zone } \\
\text { (MZ) }\end{array}$ & $9 \mathrm{yrs}$ & $4 \mathrm{yrs}$ & $5 \mathrm{yrs}$ \\
$\begin{array}{c}\text { Bay of Bengal } \\
\text { (BOB) }\end{array}$ & $10 \mathrm{yrs}$ & $3 \mathrm{yrs}$ & $7 \mathrm{yrs}$ \\
$\begin{array}{c}\text { East Pacific } \\
\text { (EPAC) }\end{array}$ & $6 \mathrm{yrs}$ & $7 \mathrm{yrs}$ & $9 \mathrm{yrs}$ \\
$\begin{array}{c}\text { West Pacific } \\
\text { (WPAC) }\end{array}$ & $9 \mathrm{yrs}$ & $6 \mathrm{yrs}$ & $9 \mathrm{yrs}$ \\
$\begin{array}{c}\text { South Indian Ocean } \\
\text { (SIO) }\end{array}$ & $9 \mathrm{yrs}$ & $8 \mathrm{yrs}$ & $7 \mathrm{yrs}$ \\
$\begin{array}{c}\text { Australia } \\
\text { (AUS) }\end{array}$ & $8 \mathrm{yrs}$ & $8 \mathrm{yrs}$ & $6 \mathrm{yrs}$ \\
$\begin{array}{c}\text { North Africa } \\
\text { (NAFR) }\end{array}$ & $9 \mathrm{yrs}$ & $8 \mathrm{yrs}$ & $3 \mathrm{yrs}$ \\
$\begin{array}{c}\text { South Africa } \\
\text { (SAFR) }\end{array}$ & $9 \mathrm{yrs}$ & $6 \mathrm{yrs}$ & $5 \mathrm{yrs}$ \\
$\begin{array}{c}\text { South America } \\
\text { (SAMR) }\end{array}$ & $9 \mathrm{yrs}$ & $9 \mathrm{yrs}$ & $6 \mathrm{yrs}$ \\
\begin{tabular}{c} 
Arabian Sea (AS) \\
\hline
\end{tabular} & $8 \mathrm{yrs}$ & $8 \mathrm{yrs}$ & $8 \mathrm{yrs}$ \\
\hline
\end{tabular}

regions of the tropics. Before applying power spectral analysis, the simulated OLR data at each grid point was detrended by removing the annual mean and the first three harmonics. The spectrum of "red noise" was computed based on lag-one autocorrelation (Mitchell et al., 1966). Figure 12 shows the power spectra of daily OLR anomalies for the selected regions from the observation and simulations with the Hack and MCA schemes. The spectra are calculated for each year seperately and then the average over ten years is obtained. The average spectra from MCA simulation show dominant spectral peaks above the respective red noise spectrum in the 20-70 day time scale in all the 10 regions. Note the improvement with the MCA scheme over the East Pacific where the spectral peak in intraseasonal time scale is closer to the observed spectral peak when compared to that of Hack scheme.

Table 1 shows the number of years in which significant spectral peak (maximum) occurs in intraseasonal time scale (20-70 days) for observation and Hack and MCA simulations. It can be clearly seen that the simulation by the MCA scheme is better over the Monsoon Zone (MZ), Bay of Bengal (BOB), and West Pacific (WPAC). Over these regions, the seasonal mean convection/precipitation and the seasonal cycle are simulated more faithfully by the MCA scheme. We also find that the MCA simulation has much higher power in the intraseasonal scale over most regions, e.g. over WPAC MCA simulates a peak power of about $120 \mathrm{wm}^{-2}$ which is about three times the observed value. This is related to the much higher precipitation (and hence more vigorous convection) that occurs over these regions in the MCA simulation (Fig. 12). Similarly over MZ the peak power is about four times the observed value. Slingo et al. (1996) suggest that the strength of intraseasonal variation in the deep tropics is related to the ability of a model to simulate the South Pacific Convergence Zone (SPCZ). We note that the SPCZ during DJF is stronger in the MCA simulation (Fig. 1), and thus the stronger intraseasonal variability exhibited by the MCA simulation is broadly in agreement with the hypothesis of Slingo et al. (1996).

\section{Simulation of Madden-Julian oscillations and pole-ward propagations}

The analysis of circulation and convection fields had shown that the CCM2 model is capable of simulating intraseasonal variability possessing some of the characteristics of the observed oscillation. This section focuses on the periodicity and propagation characteristics of simulated Madden Julian Oscillation (MJO).

\subsection{Wavenumber-frequency spectral analysis}

The data sets were seasonally detrended before applying the space-time spectral analysis. This was done by first generating the ten year mean for each day of the annual cycle and then the annual mean and the first three harmonics were

Fig. 12. The power spectral density (blue curves) of daily OLR anomalies for the 10 regions. The spectra are for the 10 year average of OLR (after detrending) anomalies for each region. The corresponding red noise spectra (dashed curves) are also shown. Please note that different scales have been used for observations, Hack and MCA 
The Power Spectral Density for 10 Regions
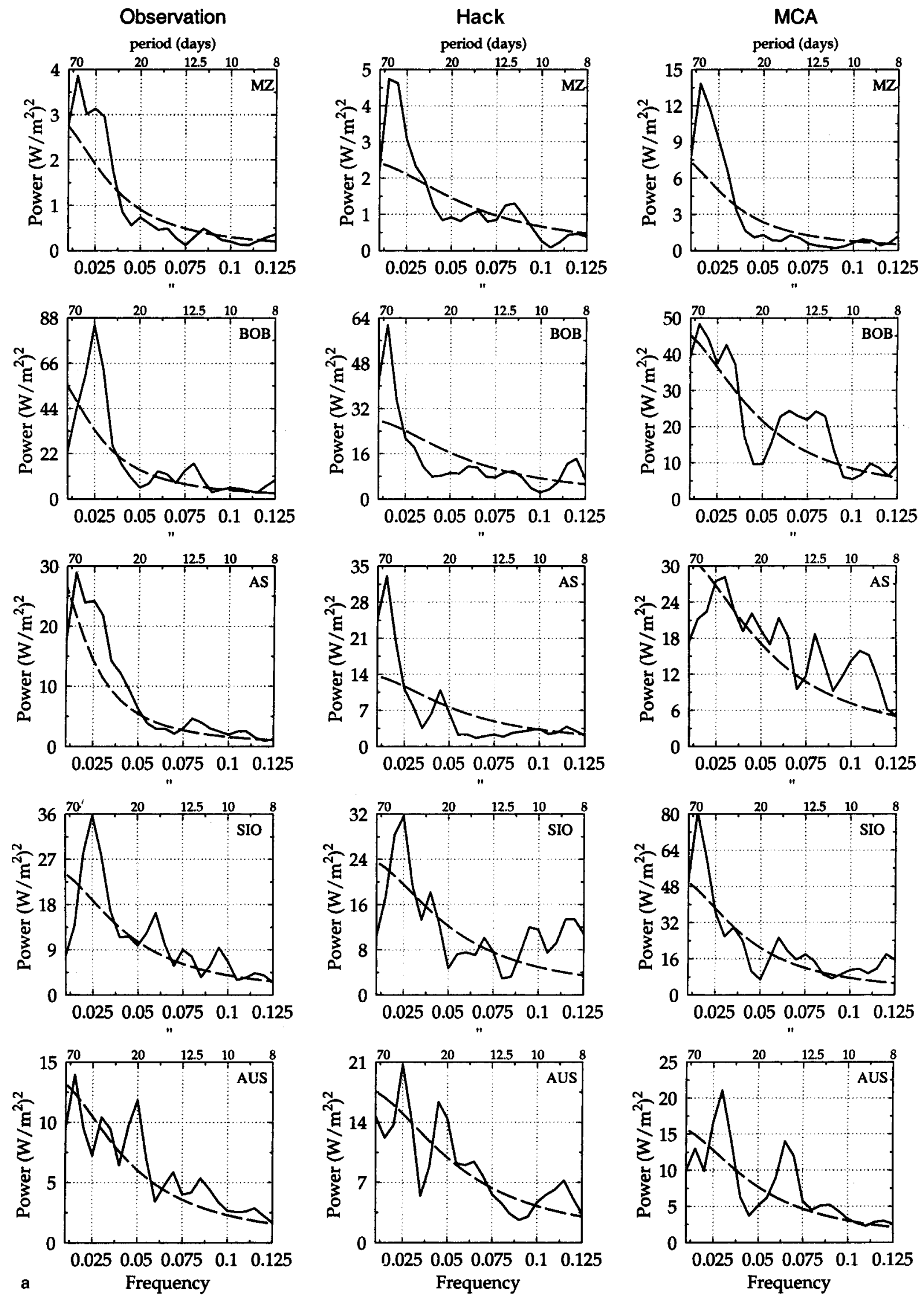


\section{The Power Spectral Density for 10 Regions}
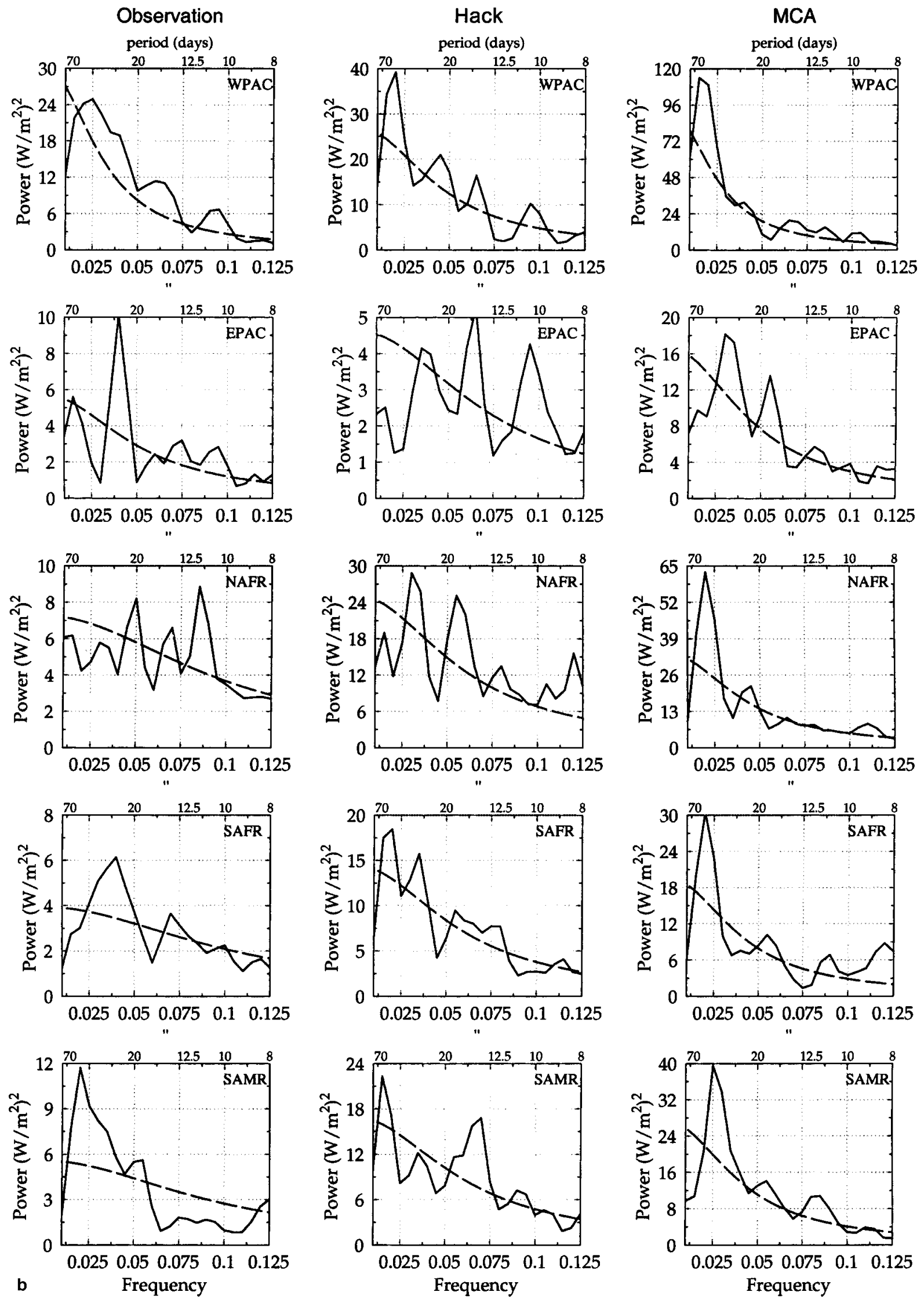
computed from this time series. The mean and the first three harmonics were then removed from the ten year time series. The space-time power spectral analysis (Hayashi, 1977; 1982) was applied to the OLR from the observation and the simulations.

The average space-time spectra for wave number 1-4 in the observed and simulated OLR are shown in Fig. 13. The average spectra for observed OLR were estimated by excluding years with a secondary higher period spectral maximum for wave number 2. The spurious secondary peak occurs in those years with large
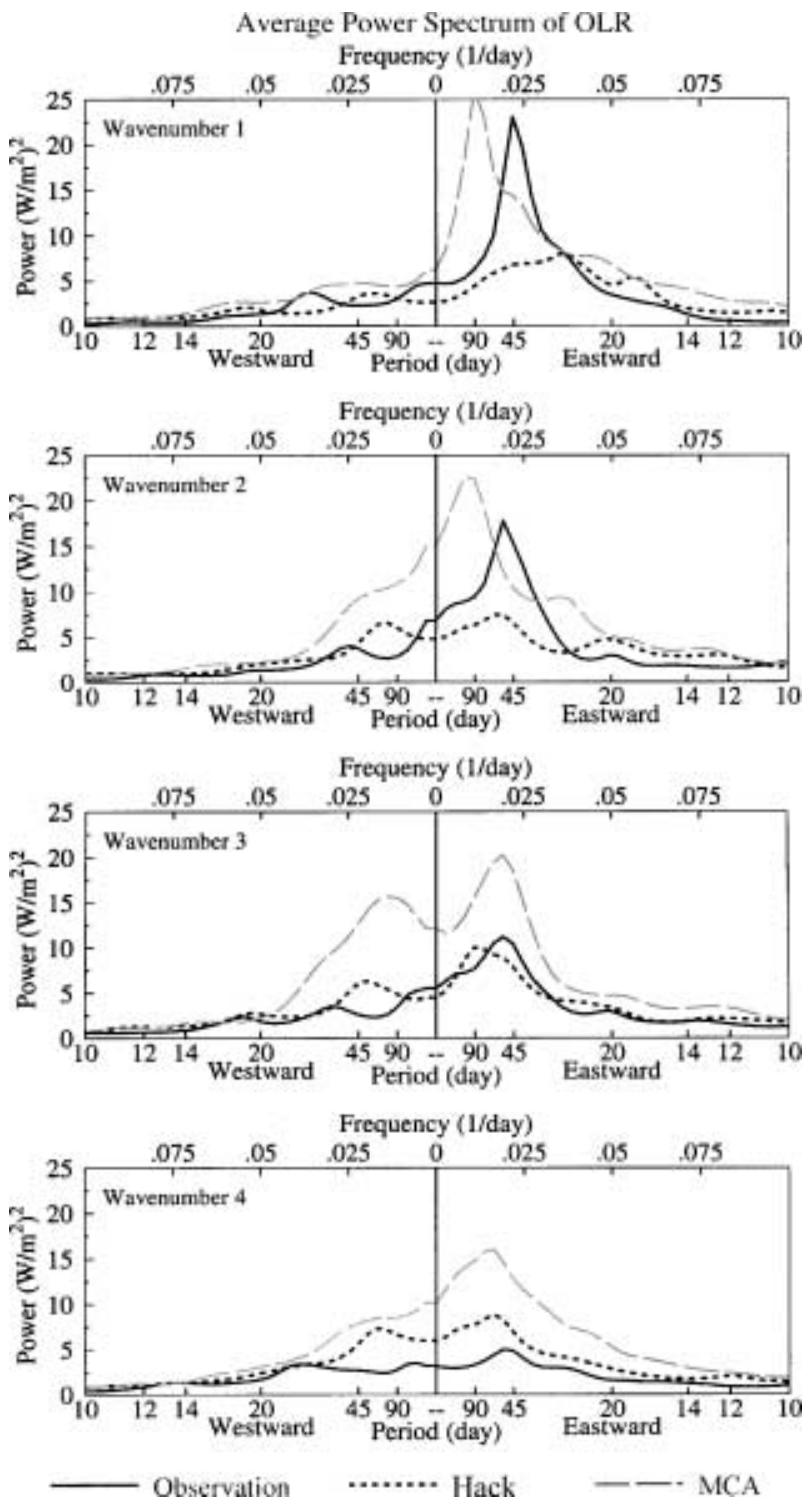

Fig. 13. Average wave number-frequency spectrum of the $10^{\circ} \mathrm{S}-10^{\circ} \mathrm{N}$ averaged OLR from observation (NOAA) and from Hack and MCA simulations for wave numbers 1 to 4 amount of missing data. Liebman and Smith (1996) filled up the missing data by linear interpolation. This leads to the spurious secondary peak in the years with large amount of missing data. The MCA simulation (Fig. 13) shows maximum variance for eastward component at wave numbers 1 and 2 with a dominant periodicity of about 55-60 days. There is a secondary eastward peak at about 50 days for wave number 3 . The largest variance occur at eastward moving wave numbers 1 and 2 and is consistent with observation. For these wave numbers the amplitudes are comparable to the observation and very little power for westward component especially for wave number 2 where the Hack simulation shows a standing wave. Thus, the partitioning of power between wave numbers 1 and 2 in the MCA scheme is similar to the observation, suggesting that some aspect of model's intraseasonal variation is consistent with the observation. In the Hack simulation, the dominant peak is associated with wave number 3 and the variance are almost equal for the eastward and westward components with wave numbers 1-4. It is also interesting to note that the energy in the lower wave numbers in with the MCA scheme is comparable to those in the observations (wave numbers 1-2), while in higher wave numbers the energy in the simulation with the Hack scheme is more realistic. It is also noteworthy that the in the lower wave numbers the peak of the spectra is at lower frequency in the MCA simulation than those in the observations while at higher wave numbers, the agreement is much closer.

\subsection{Propagation characteristics of $M J O$}

The simulation of longitudinal propagation characteristics of MJO has been studied using longitude-time cross section of OLR averaged between $10^{\circ} \mathrm{S}-10^{\circ} \mathrm{N}$ for the 10 year period. The simulated data sets were seasonally detrended by removing the mean and first three harmonics of the annual cycle, from the 10 year time series. Further, a 120 point, 20-70 days bandpass filter was applied.

Figure 14 compares the Hovmöller diagram of simulated OLR for typical years in the simulations with the Hack and MCA schemes with observations. The negative anomalies $\left(<-5 \mathrm{~W} / \mathrm{m}^{2}\right.$ 


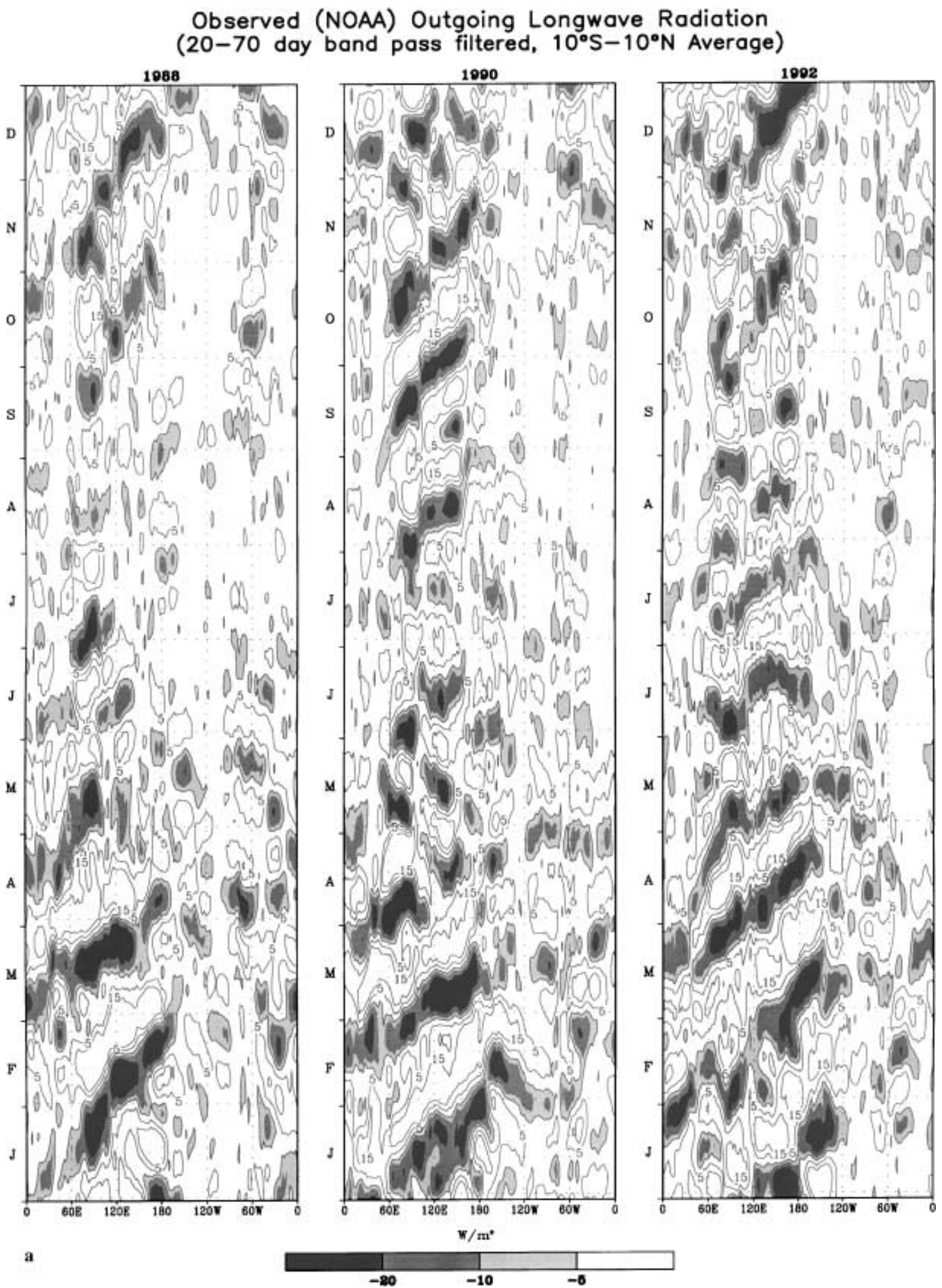

Fig. 14. Hovmöller diagram of $20-70$ day band pass filtered daily $\mathrm{OLR}$ averaged over $10^{\circ} \mathrm{S}-10^{\circ} \mathrm{N}$ from the simulation with a observations, b Hack, and c MCA scheme 


\section{Outgoing Longwave Radiation: MCA}

(20-70 day band pass filtered, $10^{\circ} \mathrm{S}-10^{\circ} \mathrm{N}$ Average)
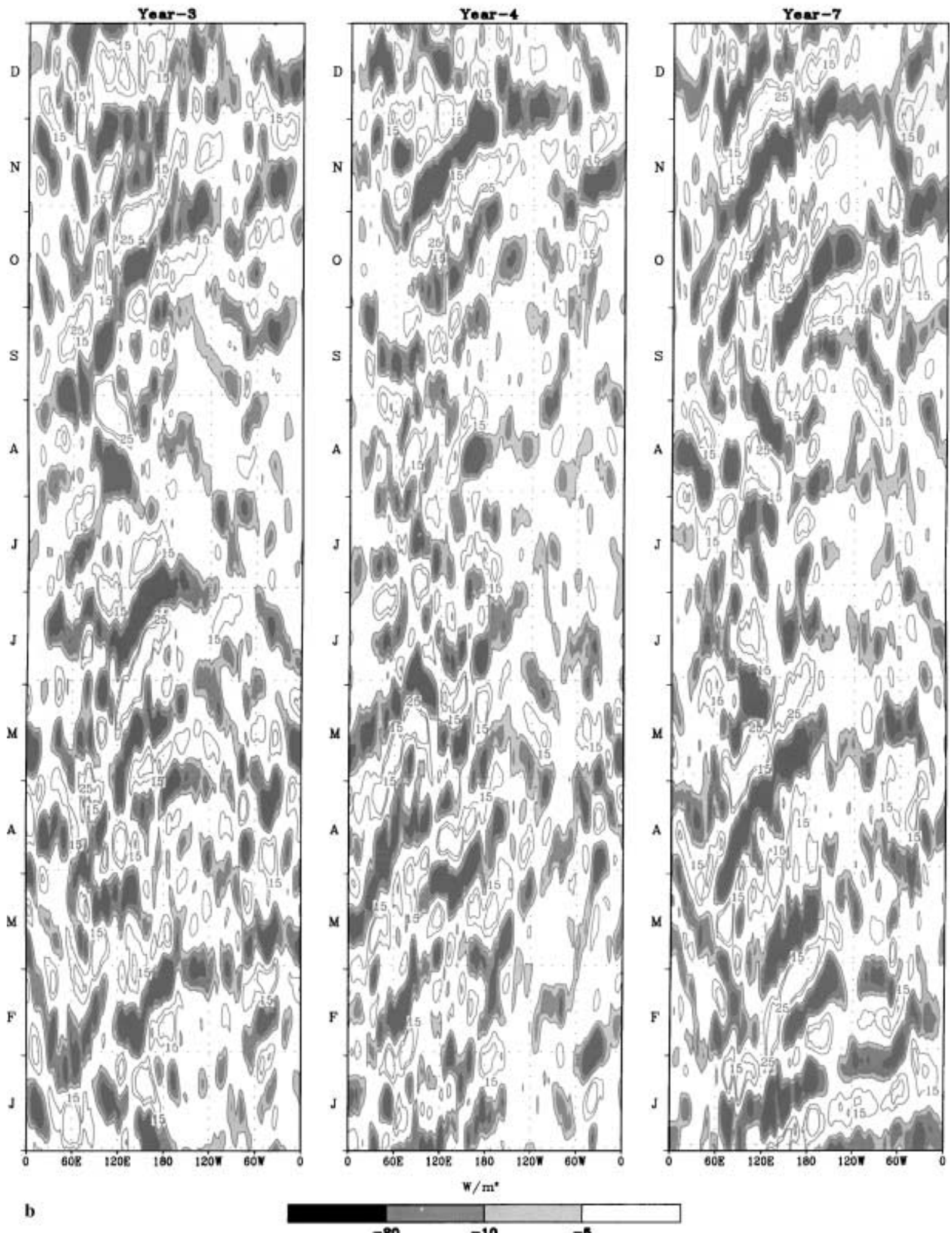

Fig. 14 (continued) 


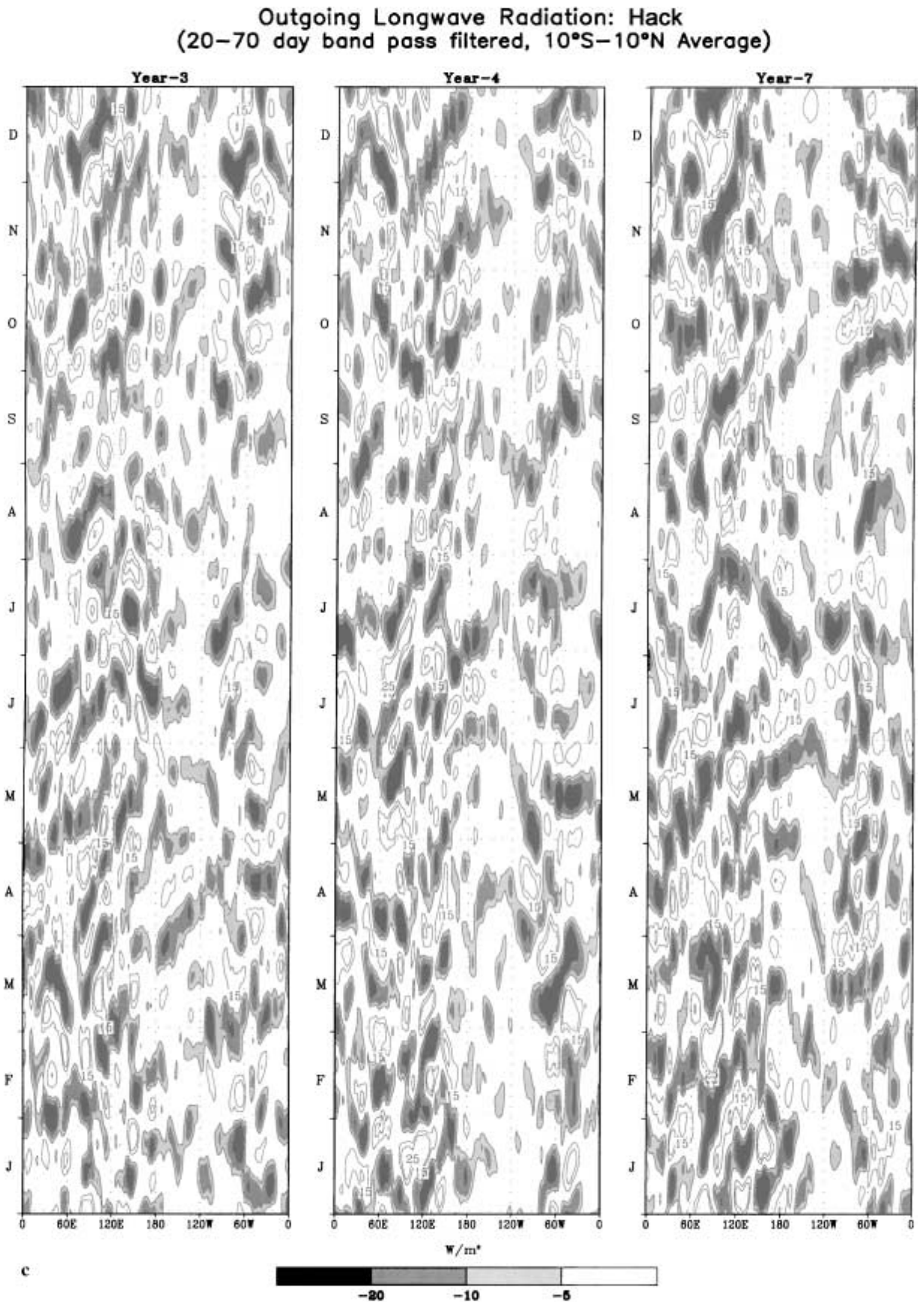

Fig. 14 (continued) 
is shaded) denote enhanced convection and positive anomalies denote reduced convection. In the observation the enhanced convection originates from the western Indian Ocean and moves towards central Pacific and decays over the colder SST regions east of the dateline. This is reproduced in simulations with both the schemes. There are year to year variation of intraseasonal oscillation. There are two important improvements in the simulations with the MCA scheme; they are (i) the speed of propagation is comparable to observation and (ii) marked seasonality in the occurrence of eastward propagations, i.e. propagations are coherent and intense during northern winter and spring seasons. The above two factors are not so obvious in the simulation with the Hack scheme.

Many studies have suggested that the phase speed of the intraseasonal oscillation depends on the vertical structure of convective heating (e.g., Lau and Peng, 1987; Sui and Lau, 1989; Park et al., 1990). Figure 15 shows the observed and simulated (by the Hack and MCA schemes) vertical profiles of vertical pressure velocity, $\omega$ averaged over Indian Ocean $\left(60^{\circ} \mathrm{E}-100^{\circ} \mathrm{E}\right)$ and Pacific $\left(120^{\circ} \mathrm{E}-180^{\circ}\right)$ for winter and spring seasons during which MJO is found to be more active. Over the Indian Ocean, the simulation with MCA scheme has much stronger heating rates than that of the Hack scheme in both the

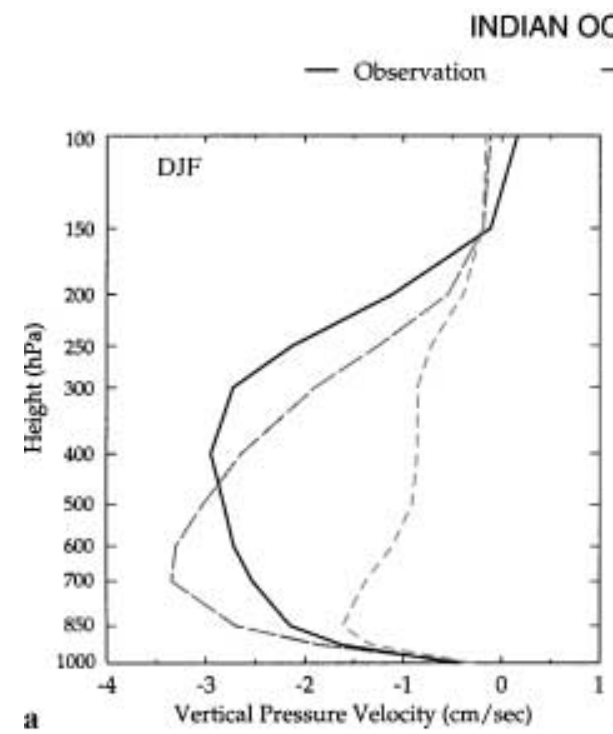

- MCA
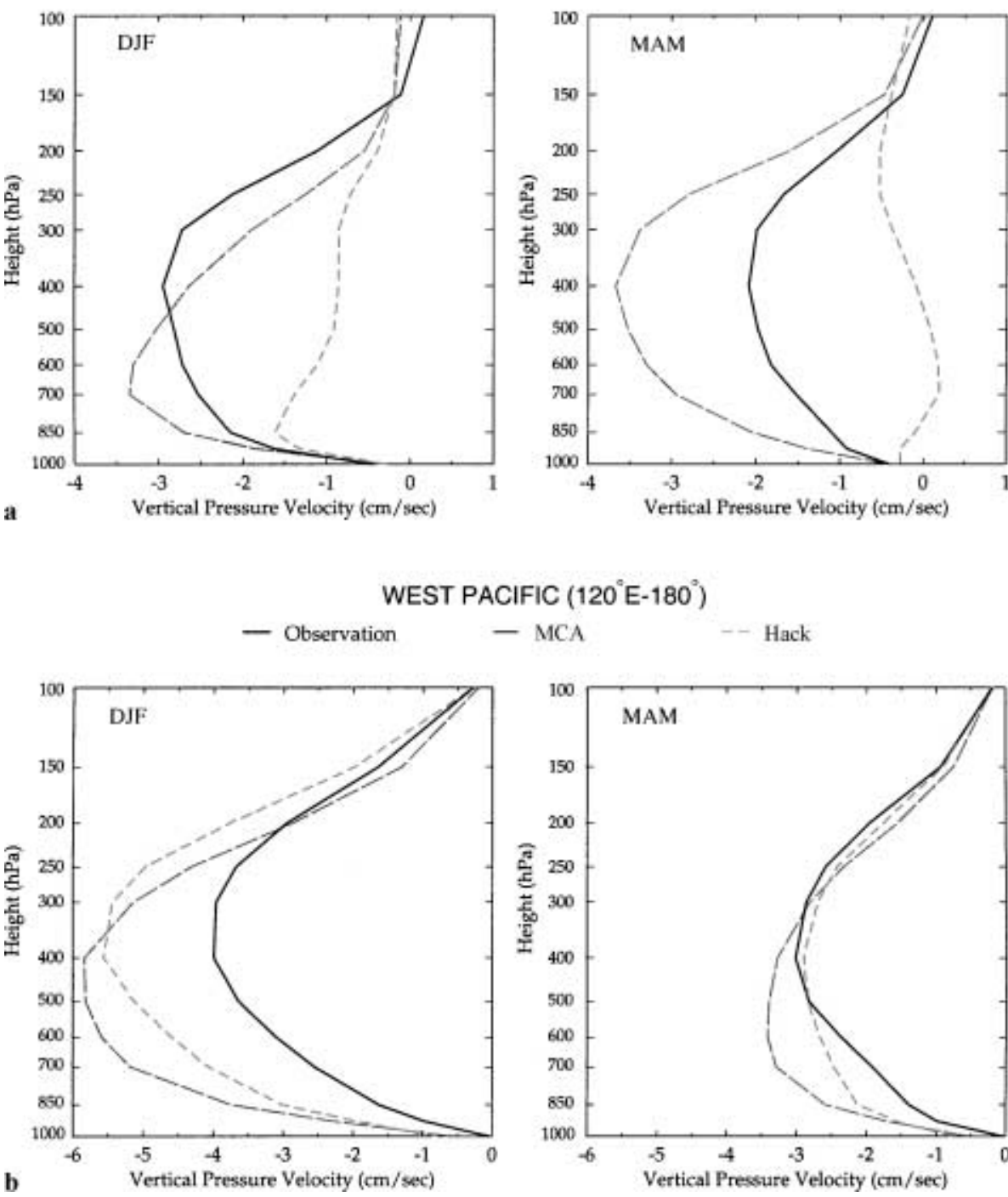

CIFIC $\left(120^{\circ} \mathrm{E}-180^{\circ}\right)$

- MCA

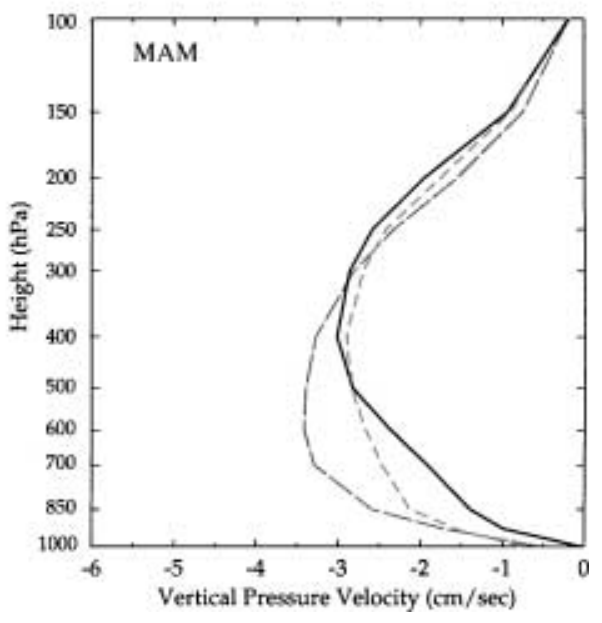

Fig. 15. Vertical profile of observed and simulated (by Hack and MCA versions) mean vertical pressure velocity $(\omega)$ for different seasons a over the Indian Ocean $\left(60^{\circ} \mathrm{E}-100^{\circ} \mathrm{E}, \quad 10^{\circ} \mathrm{S}-\right.$ $\left.10^{\circ} \mathrm{N}\right)$, and $\mathbf{b}$ over the Pacific $\left(120^{\circ} \mathrm{E}-180^{\circ} \mathrm{E}, \quad 10^{\circ} \mathrm{S}-10^{\circ} \mathrm{N}\right)$ regions 
seasons (Fig. 15). Another noticeable feature is the nearly uniform heating rate with height throughout the troposphere in the Hack simulation. In contrast, the observation and MCA simulation have their heating concentrated in the mid-troposphere with very small heating rates in the upper levels. The MCA version captures the observed feature of downward extension of the largest heating in the lower troposphere during the boreal winter and spring seasons (when the MJO is at its peak over the Eastern Hemisphere of the tropics).

According to the simple theory by Sui and Lau (1989), the downward displacement of the MCA heating profile in comparison with that of the Hack scheme should be reflected in the phase speed of the wave, with the Hack scheme's simulation having faster phase speed. This is clearly seen in the spectra of OLR (Fig. 13) from the observation and the two simulations. The power in the lower wave numbers (1 and 2) in the MCA simulation is comparable to that of the observations but the frequency is lower, resulting in slower phase speeds. Over the Pacific region extending till the dateline, the vertical distributions of heating in both the models are similar and comparable with the observed profile. However, the strength of simulated heating is different from the observation in the lower troposphere during the winter (when $\mathrm{MJO}$ is the strongest over this region) for both the models. Over the western most sector of the Pacific, the heating profile with the MCA scheme is closer to the observations in all the seasons. In the simulation with MCA scheme, there is stronger convective heating in the lower troposphere and hence leads to a more realistic seasonal mean and intraseasonal variation over the Asia-Pacific region.

\subsection{Intraseasonal variation of monsoon}

Within a season, the monsoon rainfall fluctuates: there are spells of good rain followed by dry spells. In fact, the intraseasonal variation of the summer monsoon rainfall over the Indian region is associated with the variation in location and intensity of the Tropical Convergence Zone (TCZ) over this region. The long-periods of high rainfall are often referred to as active phases of the monsoon and the periods with low or no rainfall as break phases (Krishnamurti and Bhalme, 1976; Sikka and Gadgil, 1980).

From the analysis of the satellite imagery, there appear to be two favourable locations for the TCZ: one over the warm waters of the equatorial Indian Ocean and the other over the heated continent in the vicinity of seasonal trough. Thus, the latitudinal distribution of the occurrence of the TCZ appears to be bimodal with the zone of frequent occurrence over the continent and a secondary zone over the equatorial ocean.

The variation of the observed and simulated daily rainfall averaged over the central India $\left(75^{\circ} \mathrm{E}-90^{\circ} \mathrm{E} ; 15^{\circ} \mathrm{N}-25^{\circ} \mathrm{N}\right)$ for two representative years are shown in Fig. 16a, b, respectively. The observed rainfall for two contrasting years (1972, a drought year and 1975, a good monsoon year) show that the major difference between the two years is in the duration of dry spells i.e., the break days. The drought year is characterized by more break days. The dashed line shows the 10 year daily mean rainfall with a 5-day running mean. The region selected over central India represents the mean location of the seasonal monsoon trough over India. The major difference between the two simulations is in the intensity of rainfall over the trough zone. The Hack (Fig. 16b) simulation is characterized by low rainfall over the Monsoon Zone throughout the season except during June and July. But in MCA (Fig. 16b) simulation, the distribution of rainfall is characterised with realistic fluctuations in supersynoptic time scales as high rainfall days separated from low rainfall days. The distribution in all the four months (June-September) is closer to the observation which gives rise to a realistic summer mean precipitation over this region (Fig. 3). Thus, the model with MCA scheme simulates subseasonal variation with active and break-like conditions with shifts in the rainfall patterns quite analogous to what is seen in the observations.

The above results and the simulations of mean climate and MJO from Hack and MCA versions suggest that different treatment of convection results in changes in precipitation over the entire tropics, particularly over the Indian monsoon and the East Pacific regions. This can be explained in terms of the differences between moist convective adjustment (MCA) and the mass flux scheme 

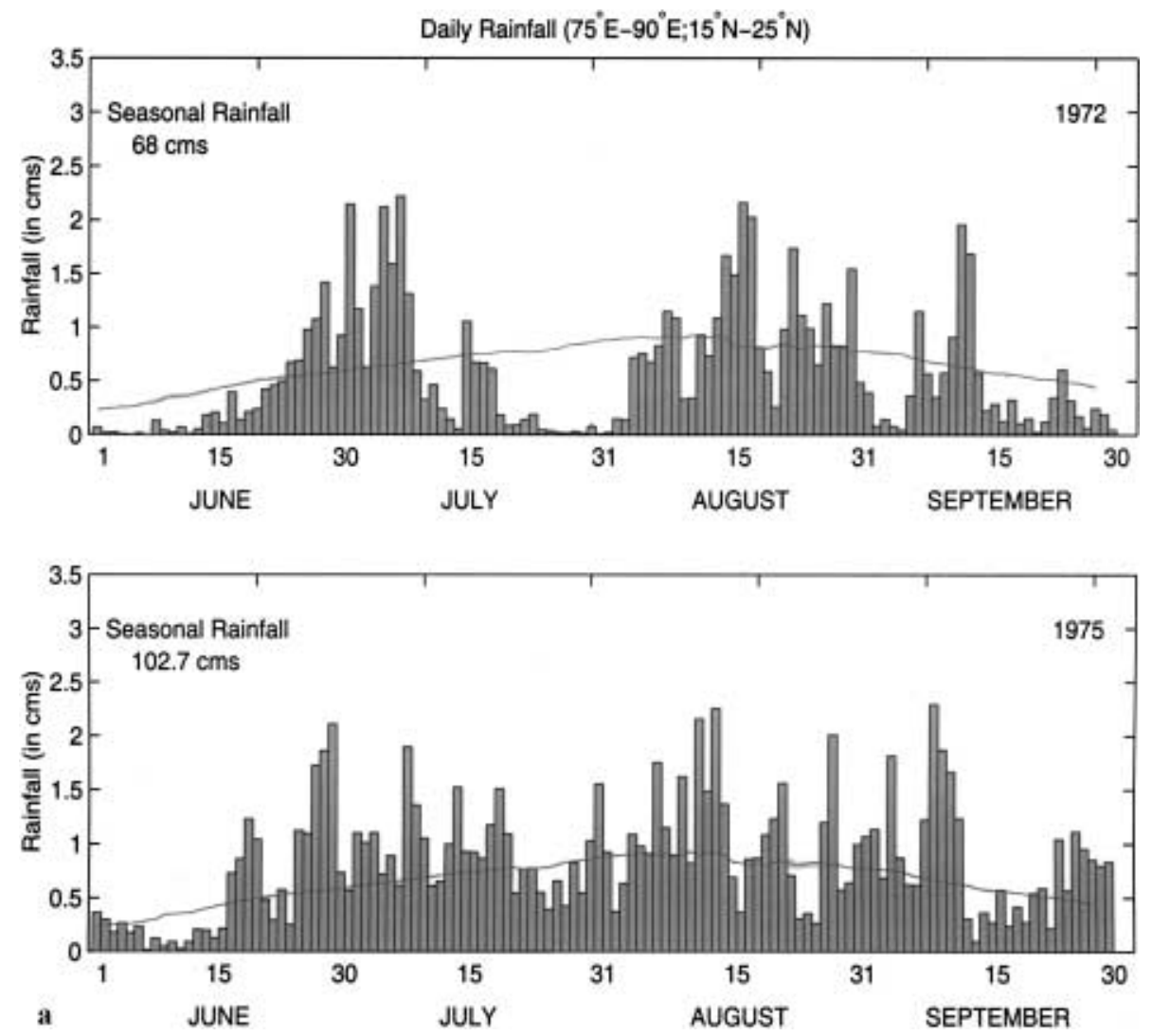

Fig. 16a. Observed IMD (for two representative years (1972 and 1975) $\mathrm{cm} \mathrm{day}^{-1}$, the dotted line indicates the long-term daily average, and b Hack and MCA simulated rainfall averaged over central India $\mathrm{mm}$ day $^{-1}$, the dashed line indicates the daily averaged climatological rainfall for the region
(Hack). In the Hack scheme, plumes can transfer moisture and energy to higher layers, while in the MCA scheme the transfer is limited to neighbouring layers. The effect of this major difference in the cumulus schemes can be seen in the vertically integrated mean moist static energy in the lower troposphere (Fig. 4). In the MCA simulation, in the lower troposphere, the vertical variation of the moist static energy is larger than that of the Hack simulation and closer to observations. This implies more vertical mixing of heat and moisture in the Hack scheme than in the MCA scheme. Hence the Hack scheme increases the vertical stability of the atmosphere and reduces precipitation. This can be seen in Fig. 17 over Africa (where Hack has higher precipitation) and the Indian monsoon (where MCA has higher precipitation) region. Over the Indian monsoon zone, the Hack scheme has lower enthalpy in the lower troposphere but due to larger mixing, it has higher enthalpy in the upper troposphere. Over the African region the Hack scheme simulates higher enthalpy over the entire troposphere.

\subsection{Meridional propagation of monsoon convective zones}

Over the continent, the TCZ revives either by insitu genesis of TCZ over the continent or by northward propagations from the ocean regions. In general, northward propagations of the oceanic TCZ leading to a revival of the continental TCZ occur at intervals of about 30-50 days. Poleward propagations account for about $50 \%$ of the revival of the continental TCZ from break condition. Examining the time-latitude diagram of daily OLR averaged over the Indian longitudes $\left(70^{\circ} \mathrm{E}-80^{\circ} \mathrm{E}\right)$ from the Hack and MCA simulations (shown in Fig. 18) we find the propagation characteristics in the MCA and Hack simulations appear to be very different. MCA simulation appears to have a more realistic simulation of both the active-break cycles over the $\mathrm{MZ}$ and the poleward propagations of the rainbands. On the contrary, Hack scheme simulates only a fluctuation of cloudbands over the peninsular region. Thus it appears that the scheme which has more realistic intraseasonal 

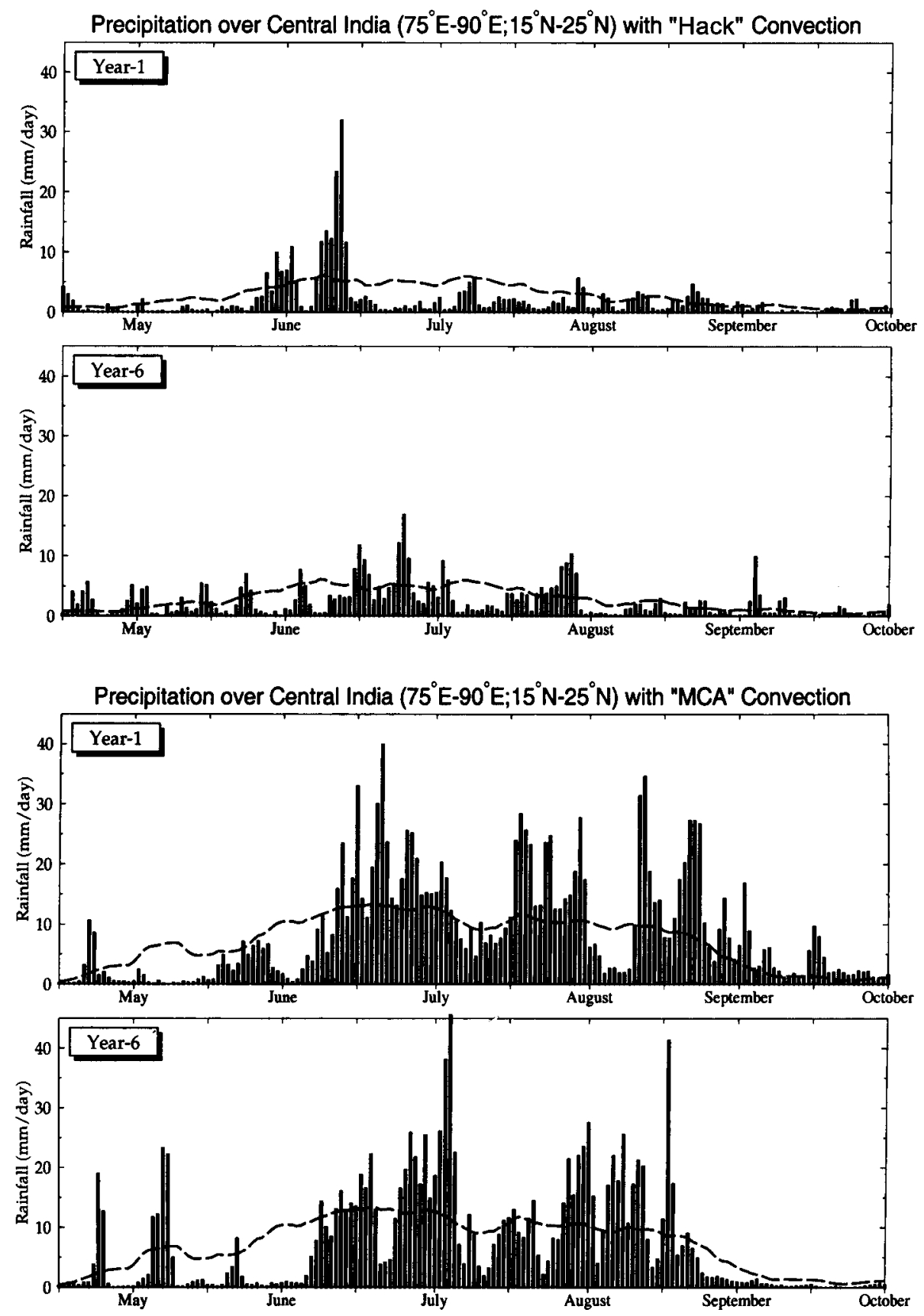

b

Fig. 16 (continued)

structure of the Indian summer monsoon also has a more realistic seasonal mean pattern. Therefore the association between realistic patterns of intraseasonal variation and seasonal pattern is not limited to the equatorial regions (as shown by Slingo et al., 1996) but can be extended to the off-equatorial regions such as the Indian monsoon zone.

Nanjundiah et al. (1992), and Gadgil and Srinivasan (1991) have suggested that the pole- ward gradient of stability (poleward region being less vertically stable than the region equatorward of the convective band) as a possible mechanism for poleward propagations in their simple models. Srinivasan et al. (1993) have further shown using the ECMWF analysis that such gradients occur in observations also. The principal reason for the occurence of the reduction of vertical stability is the increase in moisture in the lower layers of the atmosphere, which changes 

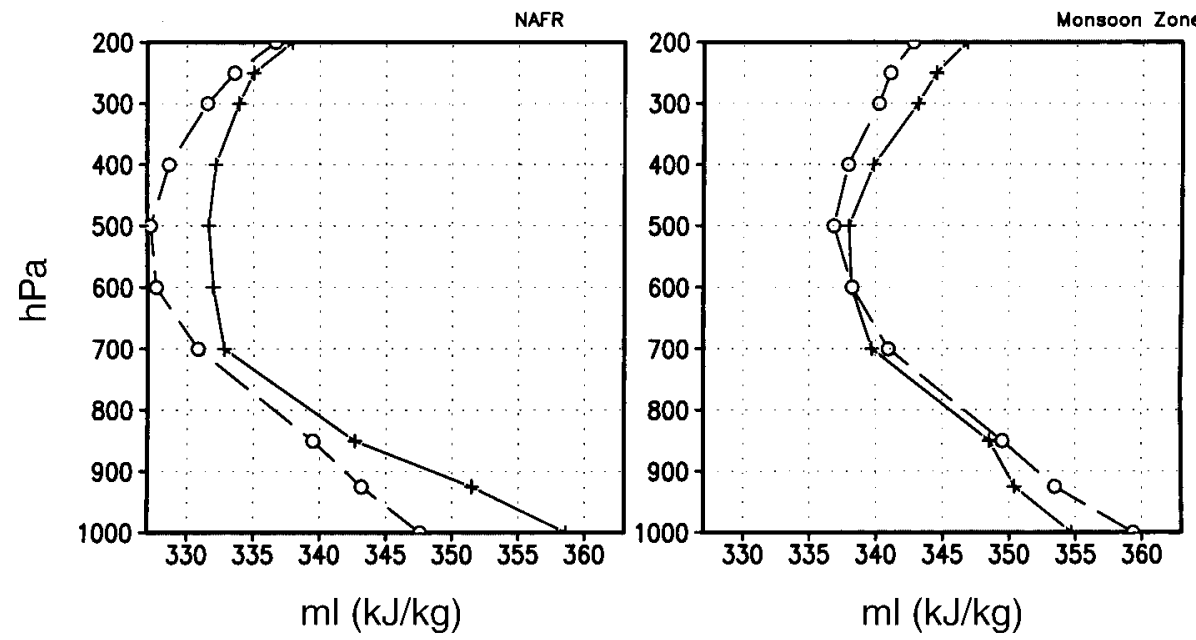

- Hack
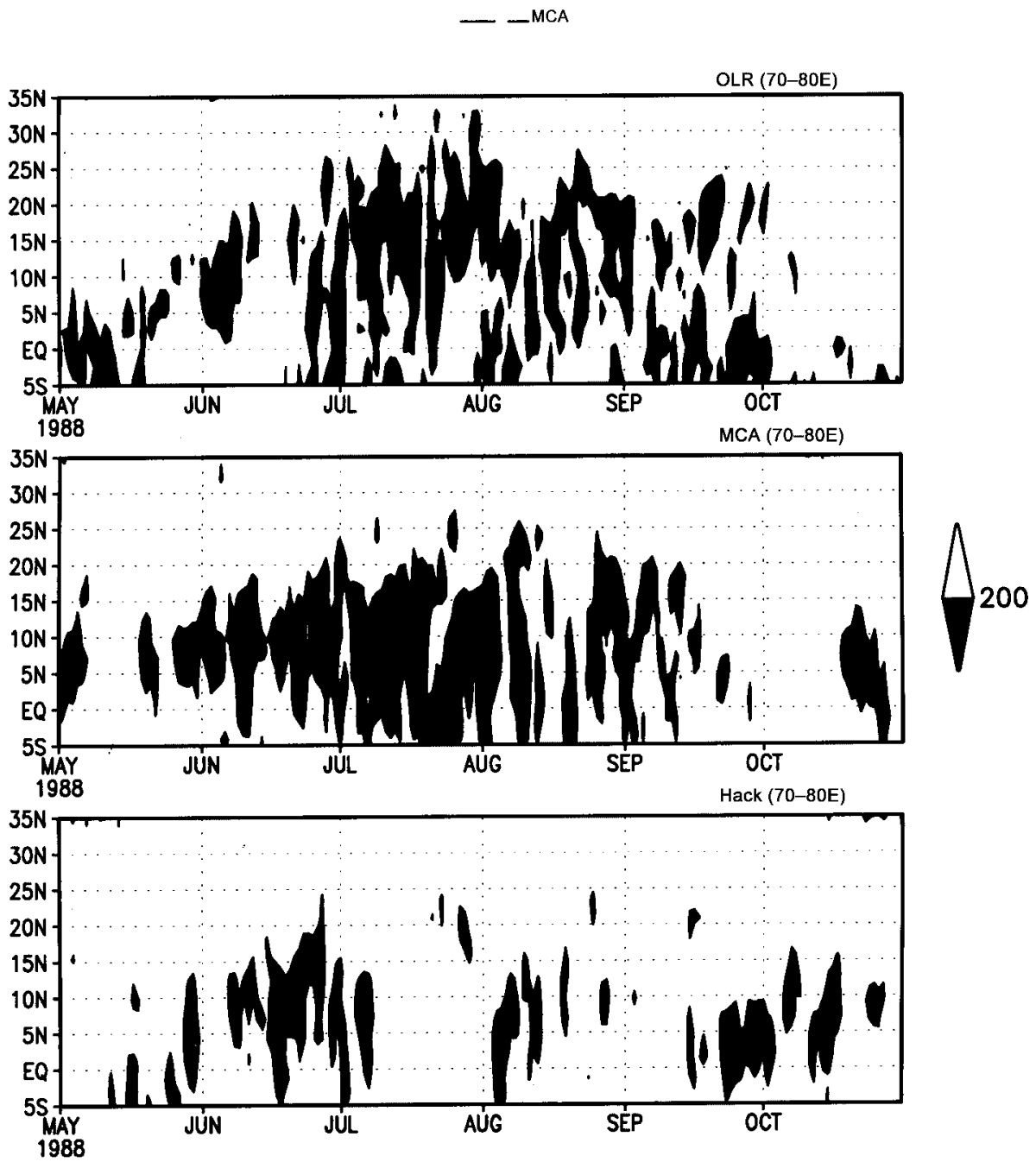

Fig. 17. Vertical structure of moist static energy $\left(\mathrm{kJ} \mathrm{kg}^{-1}\right)$ over the North African $\left(20^{\circ} \mathrm{E}-\right.$ $\left.30^{\circ} \mathrm{E}, 0^{\circ}-10^{\circ} \mathrm{N}\right)$ and the Indian monsoon regions $\left(75^{\circ} \mathrm{E}-80^{\circ} \mathrm{E}\right.$, $\left.20^{\circ} \mathrm{N}-25^{\circ} \mathrm{N}\right)$. Open circles is for simulations with the MCA scheme and "+" for the Hack scheme
Fig. 18. Time-latitude diagram of daily OLR $\left(\mathrm{W} \mathrm{m}^{-2}\right)$ between $70^{\circ} \mathrm{E}-80^{\circ} \mathrm{E}$ for a representative year from a Observation (Obs), b MCA scheme (MCA), and c Hack scheme (Hack) the profile from strongly stable during the premonsoon season to near-neutral during the monsoon period (causing the atmosphere to be more amenable for convection). Hence moist static stability in the lower troposphere is a measure of vertical stability.

The latitudinal variation of vertically integrated moist static energy $\left(m_{l}\right)$ averaged over $70^{\circ} \mathrm{E}-$ 


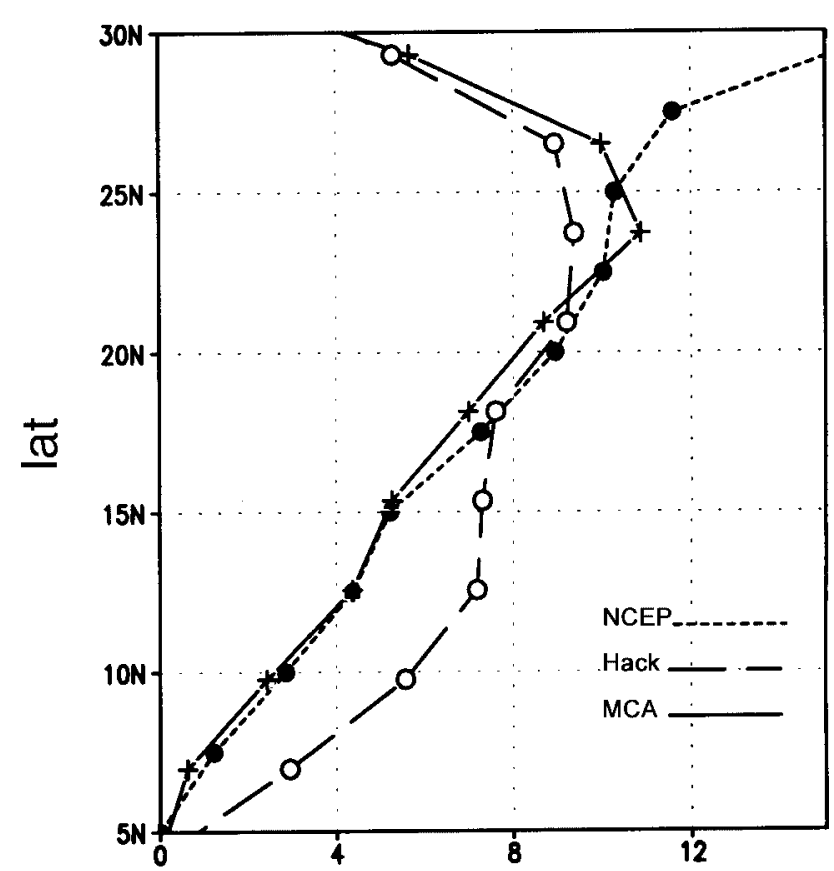

$\mathrm{ml}(\mathrm{kJ} / \mathrm{kg})$

Fig. 19. The latitudinal variation of vertically integrated moist static energy (in the layer $1000-400 \mathrm{hPa}, \mathrm{kJ} \mathrm{kg}^{-1}$ ) averaged over $92.5^{\circ} \mathrm{E}-97.5^{\circ} \mathrm{E}$ in a given month (when an active propagating event exists) from NCEP/NCAR reanalysis and Hack and MCA simulations

$85^{\circ} \mathrm{E}$ during the Indian monsoon season is shown in Fig. 19 (for simplicity of comparison of gradients as their exists a systematic bias in model simulated $m_{l}$, we have shown the difference between $m_{l}$ and its value at $5{ }^{\circ} \mathrm{N}$ ). We note that in NCEP/NCAR reanalysis and the simulation with the MCA scheme, $m_{l}$ increases poleward while with the Hack scheme this does not increase beyond $10^{\circ} \mathrm{N}$ and associated with this lack of gradient in $m_{l}$, poleward propagations of the cloudbands cease beyond this latitude. In the MCA simulation this gradient is reversed around $22^{\circ} \mathrm{N}$ beyond which there is no noticeable poleward movement. In observations, favourable gradient of $m_{l}$ exists upto $30^{\circ} \mathrm{N}$ and poleward movements of the cloudbands can be perceived upto this latitude. This clearly indicates that there exists a strong association between the presence of poleward gradient of mean moist static energy in the lower atmosphere (and the vertical instability related to this) and the occurrence of poleward propagations both in observations and model simulations. A lack of such a gradient appears to inhibit poleward propagations of TCZ in the Hack scheme.

\section{Conclusions}

In this paper we have investigated the effect of change in cumulus parameterization on the simulation of seasonal mean and intraseasonal variations of tropical climate. Simulations with two different convection schemes: (1) the mass flux scheme of Hack (1994), referred to as "Hack scheme" and (2) the moist convective adjustment scheme of Manabe et al. (1965), referred to as "MCA scheme" were studied using NCAR CCM2.

Seasonal mean simulation of rainfall over most of the tropics improved with the MCA scheme. The ability of this scheme to simulate intraseasonal variations realistically is closely associated with its ability to simulate the seasonal mean pattern realistically. This is true over the deep equatorial tropics as well also over the off-equatorial tropics such as the Indian monsoon region.

The ability of a scheme to realistically simulate the seasonal mean pattern is closely associated with its ability to simulate the mean moist static energy in the lower troposphere and precipitable water realistically. We find that the relationship between precipitable water and precipitation is closer to observations in the MCA scheme. The Hack scheme consistently underestimates precipitation (for the same value of precipitable water) vis-a-vis observations. There is a threshold value of precipitable water below which there is little precipitation (both in observations and simulations). Above this threshold, precipitation increases monotonically with precipitable water.

MCA scheme has a better simulation of the MJO characteristics. The space time spectral analysis also shows that the energy in the lower wave numbers with the MCA scheme is more realistic while the frequency is somewhat lower. At higher wave numbers Hack scheme has a more realistic spectra while the energy in the MCA simulation is higher than observations.

The ability of a scheme to simulate the poleward propagations over Indian longitudes is associated with its ability to simulate the gradient 
of $m_{l}$ realistically (i.e., $m_{l}$ increasing polewards from the near equatorial Indian Ocean). The MCA scheme simulates a more favourable gradient of $m_{l}$ and a more realistic simulation of the meridional propagations of rainbands. The MCA scheme captures the active-break cycle of the Indian summer monsoon quite well. While over most of the tropics the simulations with the MCA scheme, there are regions such as the Southern Indian Ocean and over Eastern Pacific (during DJF) where the Hack scheme appears to be possess better skills in simulating the seasonal pattern. MCA is more realistic in simulating the energy spectra at wave numbers 1 and 2, while Hack is able to simulate better the energy spectra at higher wave numbers.

MCA scheme, first used in the 1960s still appears to do better than the more sophisticated Hack scheme. This clearly suggests that the major element of the MCA scheme i.e. adjusting the vertical profile to the moist adiabat is quite realistic. Perhaps while devising more sophisticated schemes which include more cloud physics, the importance of this should not be overlooked. Based on this study we conclude that a hybrid scheme incorporating elements of both the mass-flux scheme and the convective adjustment scheme will be able to simulate tropical convection more realistically on seasonal and intraseasonal scales.

\section{Acknowledgements}

The authors wish to thank Chairman SERC-IISc for providing the computational facilities on the SP2 parallel computer. They thank Dr. H. Hendon of CIRES (Cooperative Institute for Research in Environmental Sciences) for providing the daily interpolated OLR data. This work was supported by Department of Science \& Technology, Government of India under grant no. ES/48/004/97. The parallel version of CCM2 used in this study was developed at Argonne and Oak Ridge National Laboratories under the US DoE CHAMMP (Computer Hardware and Advanced Mathematical Modelling Program for Climate Studies) and the use of the same is gratefully acknowledged. The valuable and perceptive comments of the two referees which helped in improving the paper substantially are also gratefully acknowledged.

\section{References}

Arakawa A, Schubert WH (1974) Interaction of cumulus cloud ensemble with the large-scale environment. Part I. J Atmos Sci 31: 674-701
Drake J, Foster I, Michalakes J, Toonen B, Worley P (1995) Design and performance of a Scalable Parallel Community Climate Model. Parallel Computing 21(10): 1571-1592

Duchon CE (1979) Lanczos filtering in one and two dimensions. J Appl Meteorol 18: 1016-1022

Gadgil S, Sajani S (1998) Monsoon precipitation in the AMIP runs. Clim Dyn 14: 659-689

Gadgil S, Srinivasan J (1990) Low frequency variation of tropical convergence zone. Meteorol Atmos Phys 44: $119-132$

Gill AE (1980) Some simple solutions for heat-induced tropical circulation. Quart J Roy Met Soc 106: 447-462

Gruber A, Winston JS (1978) Earth-atmosphere radiative heating based on NOAA scanning radiometer measurements. Bull Amer Meteorol Soc 59: 1570-1573

Hack JJ, Boville BA, Briegleb BP, Kiehl JT, Rasch PJ, Williamson DL (1993) Description of the NCAR Community Climate Model (CCM2). NCAR Tech. Note, NCAR/TN-382+STR, NTIS PB93-221802/AS, National Center for Atmos Res Boulder, CO, 108pp

Hack JJ (1994) Parameterization of moist convection in the National Centre for Atmospheric Research community climate model (CCM2). J Geophys Res 99: 5551-5568

Hack JJ, Boville BA, Kiehl JT, Rasch PJ, Williamson DL (1994) Climate statistics from the National Centre for Atmospheric Research Community Climate Model CCM2. J Geophys Res 99: 20,785-20,813

Hurrell JW (1995) Comparison of NCAR Community Climate Model (CCM) climates. Clim Dyn 11: 25-50

Hahman AN, Ward DM, Dickinson RE (1995) Land-surface temperature and radiative fluxes response of the NCAR CCM2/Biosphere-atmosphere transfer scheme to modifications in the optical properties of clouds. J Geophys Res 100: 23,239-23,252

Hayashi Y (1977) Space-time power spectral analysis using the maximum entropy method. J Meteorol Soc Japan 55(4): 415-420

Hayashi Y (1982) Space-time spectral analysis and its application to atmospheric waves. J Meteorol Soc Japan 60: 156-171

Itoh H (1989) The mechanism for the scale selection of tropical intraseasonal oscillations. Part I: Selection of wavenumber 1 and three-scale structure. J Atmos Sci 46: 1779-1798

Kalney E, Iredell M, Saha S, White G, Woollen J, Zhu Y, Chelliah M, Ebisuzaki W, Higgins W, Janowiak J, Mo KC, Ropelewski C, Wang J, Leetmaa A, Reynolds R, Jenne R, Joseph D (1996) The NCEP/NCAR 40year reanalysis project. Bull Amer Meteorol Soc 77: 437-471

Kiehl JT, Hack JJ, Briegleb BP (1994) The simulated Earth radiation budget of the NCAR CCM2 and comparisons with the Earth Radiation Budget Experiment (ERBE). J Geophys Res 99: 20,815-20,827

Krishnamurti TN, Bhalme HN (1976) Oscillations of a monsoon system. Part 1. Observational aspects. J Atmos Sci 33: 15-26 
Kuo HL (1974) Further studies of the parameterization of the influence of cumulus convection on large scale flow. J Atmos Sci 31: 1232-1240

Lau K-M, Peng L (1987) Origin of low-frequency (intraseasonal) oscillations in the tropical atmosphere. Part I: Basic theory. J Atmos Sci 44: 950-972

Liebmann B, Smith CA (1996) Description of a complete (interpolated) outgoing longwave radiation dataset. Bull Amer Meteorol Soc 77: 1275-1277

Lieberman RS, Leovy CB, Boville BA, Briegleb P (1994) Diurnal heating and cloudiness in the NCAR Community Climate Model (CCM2). J Climate 7: 869-889

Manabe S, Smagorinsky J, Strickler RF (1965) Simulated climatology of a general circulation model with a hydrologic cycle. Mon Wea Rev 93: 769-798

Mitchell JM, Ozerdzeevski B, Flohn H, Hofmeyr HL, Lamb HH, Rao KN, Wallen CC (1966) Climate change. WMO Technical Note, No. 79, Geneva, WMO

Murakami T, Nakazawa T, He J (1984) On the 40-50 day oscillations during the 1979 Northern Hemisphere summer. Part 1. Phase propagation. J Meteorol Soc Japan 62: 440-468

Nanjundiah RS (2000) Impact of moisture transport on the simulated tropical rainfall in a General Circulation Model. Clim Dyn 16: 303-317

Nanjundiah RS, Srinivasan J (1999) Anomalies of precipitable water-vapor and vertical stability during El-Niño. Geophys Res Letters 26: 95-98

Nanjundiah RS, Srinivasan J, Gadgil S (1992) Intraseasonal variation of the Indian summer monsoon. Part 2: Theoretical aspects. J Meteorol Soc Japan 70: 529-550

Neelin JD, Held IM (1987) Modeling tropical convergence based on the moist static energy budget. Mon Wea Rev 115: 3-12

Park C-K, Straus DM, Lau K-M (1990) An evaluation of the structure of tropical intraseasonal oscillations in three general circulation models. J Meteorol Soc Japan 68(4): 403-417

Shea DJ, Trenberth KE, Reynolds RW (1990) A global monthly sea-surface temperature climatology. NCAR Tech Note, NCAR/TN-345+STR, National Center for Atmos Res Boulder, CO, 167pp

Sikka DR, Gadgil S (1980) On the maximum cloud zone and the ITCZ over Indian longitudes during the southwest monsoon. Mon Wea Rev 108: 1840-1853

Slingo JM, Mohanty UC, Tiedtke M, Pearce RP (1988) Prediction of the 1979 summer monsoon onset with modified parameterization schemes. Mon Wea Rev 116(2): 328-346

Slingo JM, Sperber KR, Boyle JS, Ceron J-P, Dix M, Dugas B, Ebisuzaki W, Fyfe J, Gregory D, Gueremy J-F, Hack J, Harzallah A, Inness P, Kitoh A, Lau K-M,
McAvaney B, Madden RA, Mathews A, Palmer TN, Park C-P, Randal D, Renno N (1996) Intraseasonal oscillation in 15 atmospheric general circulation models. Results from an AMIP diagnostic subproject. Clim Dyn 12: 325-357

Sperber KR, Palmer TN (1996) Interannual variation of rainfall variability in general circulation model simulations associated with the Atmospheric Model Intercomparison Project. J Climate 9: 2727-2750

Srinivasan J, Gadgil S, Webster PJ (1993) Meridional propagation of large scale monsoon convective zones. Meteorol Atmos Phys 52: 15-35

Srinivasan J, Smith GL (1996) Meridional migration of tropical convergence zones. J Appl Meteorol 35: 1189-1202

Srinivasan J (1997) Deep cloud clusters in the tropics. J Indian Inst Sci 77: 237-255

Sud YC, Chao WC, Walker GK (1992) Role of cumulus parameterization scheme in maintaining atmospheric circulation and rainfall in the nine-layer Goddard Laboratory for Atmospheres General Circulation Model. Mon Wea Rev 120: 594-611

Sui C-H, Lau K-M (1989) Origin of low-frequency (intraseasonal) oscillations in the tropical atmosphere. Part II: Structure and propagation by mobile wave-CISK modes and their modification by lower boundary forcings. J Atmos Sci 46: 37-56

Taylor KE (2001) Summarizing multiple aspects of model performance in a single diagram. J Geophys Res (forthcoming)

Tokioka T, Yamazaki K, Kitoh A, Ose T (1988) The equatorial 30-60 day oscillation and the ArakawaSchubert penetrative cumulus parameterization. J Meteorol Soc Japan 66: 883-901

Wang W, Schlesinger ME (1999) The dependence on convection parameterization of the tropical intraseasonal oscillation simulated by the UIUC 11-layer atmospheric GCM. J Climate 12: 1423-1457

Xie P, Arkin PA (1997) Global precipitation: A 17-year monthly analysis based on gauge observations, satellite estimates, and numerical model outputs. Bull Amer Meteorol Soc 78(11): 2539-2558

Zhang GJ (1994) Effect of cumulus convection on the simulated monsoon circulation in a general circulation model. Mon Wea Rev 122: 2022-2038

Zhang MH, Hack JJ, Kiehl JT, Cess RD (1995) Diagnostic study of climate feedback processes in atmospheric general circulation models. J Geophys Res 99: 5525-5537

Authors' address: Dr. Ravi S. Nanjundiah, K. Rajendran and J. Srinivasan, Center for Atmospheric and Oceanic Sciences, Indian Institute of Science, Bangalore 560012 , India (E-mail: ravi@caos.iisc.ernet.in) 